\title{
Gene Expression Profiling of \\ Human Adipose Tissue Stem Cells during 2D versus 3D Adipogenesis
}

\author{
Fatema Tuj Zohora $^{a} \quad$ Alyaa Isam Aldebs $^{a} \quad$ Nasim Nosoudi $^{b} \quad$ Surinder Pal Singh ${ }^{c}$ \\ Jaime Eduardo Ramirez-Vick ${ }^{a}$ \\ a Department of Biomedical, Industrial, and Human Factors Engineering, Wright State University, Dayton, OH, USA; \\ ${ }^{b}$ Biomedical Engineering Program, Marshall University, Huntington, WV, USA; \\ 'CSIR-National Physical Laboratory, Dr. K.S. Krishanan Marg, New Delhi, India
}

\section{Keywords}

Adipose tissue-derived stem cells · Gene expression ·

3D culture $\cdot$ Adipogenesis

\begin{abstract}
Much of the current understanding on molecular and cellular events of adipose developmental biology comes from monolayer cell culture models using preadipocyte cell lines, although in vivo adipose tissue consists of a much more complex three-dimensional microenvironment of diverse cell types, extracellular network, and tissue-specific morphological and functional features. Added to this fact, the preadipocytes, on which the adipogenesis mechanisms are mostly explored, possess some serious limitations (e.g., time of initial subculture and adipogenic differentiation time), which, perhaps, can efficiently be replaced with progenitor cells such as adipose tissue-derived stem cells (ASCs). With the objective of developing a better in vitro model for adipose developmental biology, this project involves gene expression profiling of human ASCs (hASCs) during their differentiation to adipocytes in a 2D versus 3D culture model. This transcriptional-level analysis revealed that gene expression patterns of adipogenesis-induced hASCs in a 3D selfassembled polypeptide hydrogel are relatively different from the $2 \mathrm{D}$ monolayered cells on plastic hard substrate.
\end{abstract}

Moreover, analysis of adipogenic lineage progression 9 days after adipogenic induction shows earlier differentiation of hASCs in 2D over their 3D counterparts. However, differentiation in 2D shows some unexpected behavior in terms of gene expression, which does not seem to be related to adipogenic lineage specification. Since hASCs are already being used in clinical trials due to their therapeutic potential, it is important to have a clear understanding of the molecular mechanisms in an in vivo model microenvironment like the one presented here.

c) 2020 S. Karger AG, Basel

\section{Introduction}

Adipose tissue dysregulation is one of the critical issues during the development of the metabolic syndrome (i.e., elevated blood pressure, increased blood sugar, excess body fat around the waist, and abnormal cholesterol or triglyceride levels, increasing the risk of heart disease, stroke, and diabetes.). Adipose tissue is one of the largest connective tissues, exhibiting a complex microenvironment comprised of a stromal vascular fraction of multiple cell types, including mesenchymal stem cells (MSCs), preadipocytes, adipocytes, fibroblasts, pericytes, endothelial cells, vascular smooth muscle cells, resident monocytes, macrophages,

\section{KARGER}

(C) 2020 S. Karger AG, Basel

karger@karger.com

www.karger.com/cto
Jaime E. Ramirez-Vick

Wright State University

3640 Colonel Glenn Highway

Dayton, OH 45435 (USA)

jaime.ramirez-vick@wright.edu 
and lymphocytes [Zuttion et al., 2013]. Moreover, adipose tissue possesses distinct morphological and functional features depending on their anatomical location [Peinado et al., 2010], which give rise to a complex signaling cascade and make it difficult to study the network of mechanisms involved in adipogenesis. An in vitro cell culture model capable of allowing for this complexity would be a valuable platform to understand key molecular and cellular aspects of adipogenesis [Ruiz-Ojeda et al., 2016].

Primary adipocytes as well as the adipose tissue have been used as in vitro models to shed light on adipocyte biology. However, these models possess various limitations, which might lead to inaccurate views of these cells, including limited expansion in culture, difficulty with DNA transfection, large triglyceride content that interferes with microscopy and biochemical assays, and phenotypic and genotypic variation depending on tissue source and species, among others [Wolins et al., 2006]. In addition, widely used 3T3-L1 preadipocytes for in vitro adipogenic studies require 2 weeks to differentiate into adipocytes and show a drastically reduced adipogenic potential in culture [Wolins et al., 2006]. ASCs, which possess MSC-like behavior (i.e., extensive proliferation, multipotency, and immunomodulatory properties) and the capacity to form in vivo-like unilocular mature adipocytes [Baptista et al., 2009] - unlike 3T3-L1 cells which develop into multilocular adipocytes [Wang et al., 2014] - might be a valuable alternative to study adipose developmental biology and associated pathologies like obesity or diabetes.

Furthermore, in vitro modeling of the adipose tissue microenvironment is crucial for studying adipogenesis. Although, well-established 2D monolayer cultures are successful in revealing many fundamental mechanisms involved during adipogenesis, they have failed to capture the complexity of in vivo adipose 3D tissue. The third dimension not only alters the spatial distribution of adhesion receptors that cells express upon interaction with surrounding cells and extracellular matrices (ECMs), it also puts a physical constraint on intracellular cytoskeleton protein organization [Edmondson et al., 2014]. The 3D microenvironment is expected to trigger specific mechanotransduction pathways that manipulate cellular functions via changes in adhesion mechanisms, cell distribution, size, shape, and spreading, and temporal expression of genes/proteins. Moreover, its use in applications such as transplantation therapy is limited since it requires engineered tissue to be in a transplantable substrate mimicking tissue-specific mechanical strength, cellular diversity, and ECM proteins, or other necessary signaling molecules, not possible with the cells attached on a flat substrate.
Therefore, a great number of biomaterials and scaffolds have been developed, trying to mimic these tissuespecific microenvironments. Among these biomaterials, natural or synthetic hydrogels consisting of cross-linked polymeric networks with a high water retention capacity have been shown to effectively capture many aspects of the native cellular microenvironments [Tibbitt and Anseth, 2009]. In the present study, we focus on identifying differentially expressed genes during adipogenesis in hASCs and the corresponding signaling pathways affected by culturing cells in $2 \mathrm{D}$ versus $3 \mathrm{D}$ microenvironments. The 3D cell microenvironment used is based on the PuraMatrix $^{\mathrm{TM}}$ hydrogel, which is based on molecularly designed synthetic oligopeptides made up of a recurrent series of 16 residues with arginine $\left(\mathrm{R}^{+}\right)$, alanine $(A$; nonpolar), aspartate $\left(\mathrm{D}^{-}\right)$, and once again, arginine (RADARADA..., or simply RADA16) [Yokoi et al., 2005]. In the presence of monovalent salts or physiological solutions, these amphiphilic oligopeptides spontaneously assemble to form nanofibrous networks with $\beta$-sheet structures through ionic bonds between adjacent arginine and aspartate as well as hydrophobic interactions between alanine residues [Zhang et al., 1993, 1995]. The hydrogel is completely synthetic with a consistent composition compared to the widely used biologically derived biomaterials, such as Matrigel and collagen, which show lot-wise variability and complexity in composition [Zhao and Zhang, 2004].

Furthermore, the optimized hydrogel PuraMatrix ${ }^{\mathrm{TM}}$ was combined with hASCs as a tissue construct to study adipogenesis. Considering that cells grown in $3 \mathrm{D}$ can restore their in vivo regulatory activities, 3D hASC cultures might provide a promising approach for studying differentiation complexities in a close to physiological microenvironment.

\section{Materials and Methods}

Experimental Design

The 2 major experimental groups were: (1) hASCs seeded on 2D plates and (2) hASCs encapsulated in 3D hydrogels. The entire experiment was divided into 2 sections. The first part involves cell proliferation with the progression of adipogenesis differentiation in $2 \mathrm{D}$ versus $3 \mathrm{D}$. The second section consists of a comparative study of gene expression in $2 \mathrm{D}$ versus $3 \mathrm{D}$ hASCs models 9 days after inducing adipogenic differentiation.

hASCs Culture/Subculture

hASCs were purchased from Lonza (Walkersville, MD, USA). According to the manufacturer, these cells were isolated from nondiabetic adult lipoaspirates and express CD13, CD29, CD44, 
CD73, CD90, CD105, and CD166 and do not express CD14, CD31, and CD45 until passage 5. Passage 1 cells were subcultured until passage 4 and maintained in human MSC (hMSC) expansion media (ScienCell, Carlsbad, CA, USA) at $37^{\circ} \mathrm{C}$ in $5 \% \mathrm{CO}_{2}$. The medium was changed every 2-4 days based on cell confluency. Upon full confluency at passage 4 , cells were cultured for $2 \mathrm{D}$ and $3 \mathrm{D}$ experimental analysis.

\section{$2 D$ versus $3 D$ Culture}

For the 2D culture, hASCs were seeded in tissue culture-treated plastic well plates. For mimicking the $3 \mathrm{D}$ tissue microenvironment, cells were encapsulated within $0.5 \%(\mathrm{w} / \mathrm{v})$ self-assembling peptides (PuraMatrix ${ }^{\mathrm{TM}}$ (Corning, NY, USA) and placed in nontreated plastic well plates. PuraMatrix ${ }^{\mathrm{TM}}$ consists of $1 \%(\mathrm{w} / \mathrm{v})$ standard amino acids and 99\% water. hASC encapsulation was performed according to the manufacturer's protocol with a minor modification. Briefly, PuraMatrix stock ( $1 \% \mathrm{w} / \mathrm{v})$ was bath sonicated for $30 \mathrm{~min}$ to reduce the viscosity, followed by aliquoting the required amount from the stock to mix with an equal volume of cell suspension in $20 \%$ sucrose at a $1: 1$ ratio. Then, $100 \mu \mathrm{L}$ of a cellhydrogel mixture were dispensed in the center of the nonadherent 24-well plate. Afterwards, hMSC expansion media were added quickly to assemble the PuraMatrix hydrogel. The seeded cells were maintained either in normal MSC growth media for control or treated with biochemical induction factors for adipogenic differentiation. For 3D culture, two-thirds of the medium were replaced every 2 days, whereas in $2 \mathrm{D}$ culture, almost all medium was replaced every 3 days. The initial cell seeding density was 100,000 cells $/ 1.9 \mathrm{~cm}^{2}(2 \mathrm{D})$ or 100,000 cells $/ 100 \mu \mathrm{L}$ of total gel (3D) for all analysis.

\section{Biochemical Induction of Adipogenic Differentiation}

For adipogenic induction, proprietary hMSCs (ScienCell) growth medium was supplemented with $10^{-7} \mathrm{M}$ dexamethasone (Acros Organics, Bridgewater, NJ, USA), 0.5 mM IBMX (Sigma, St. Louis, MO, USA), $60 \mu \mathrm{M}$ indomethacin (Alfa Aesar, Haverhill, MA, USA), and $10 \mu \mathrm{g} / \mathrm{mL}$ insulin (Santa Cruz Biotech, Dallas, TX, USA). This method was used with cells analyzed for adipogenesisinduced cell proliferation, actin staining, and adipogenic differentiation staining. However, for adipogenic gene expression analysis, the above-mentioned method was revised with the addition of 250 $\mu \mathrm{M}$ L-ascorbate-2-phosphate [Choi et al., 2008] (Sigma) and a slight increase in dexamethasone concentration, from $10^{-7} \mathrm{M}$ to $10^{-6} \mathrm{M}$. Control hASCs were maintained in normal hMSC growth medium (ScienCell). The medium change was performed as mentioned in the above section ( $2 \mathrm{D}$ vs. $3 \mathrm{D}$ culture) for both $2 \mathrm{D}$ and $3 \mathrm{D}$ cells.

\section{Cell Viability and Proliferation}

The lactate dehydrogenase (CytoTox $96^{\circledR}$ nonradioactive cytotoxicity assay kit; Promega, Madison, WI, USA) colorimetric cytotoxicity assay was used to quantify cell viability and proliferation. For cell proliferation during differentiation, the seeded/encapsulated cells were induced at the onset of day 3 , and the changes in cell number were measured on days 7 and 12 of initial culture. For proliferation analysis at each time point, cultured cells were first washed with Dulbecco's phosphate buffered saline (DPBS) and then incubated at $37^{\circ} \mathrm{C}$ with $50 \mu \mathrm{L}(4 \mathrm{mg} / \mathrm{mL})$ type I collagenase per well for $30 \mathrm{~min}$. After incubation, the samples were lysed with $500 \mu \mathrm{L} 1 \times$ Triton X-100, followed by bath sonication for $1 \mathrm{~h}$. Then, lysed samples were centrifuged at high speed for $5 \mathrm{~min}$. Next, 50 $\mu \mathrm{L}$ of supernatant and $50 \mu \mathrm{L}$ of lactate dehydrogenase substrate were added to a flat-bottom clear 96-well plate and kept on an orbital shaker for $30 \mathrm{~min}$. The reaction was stopped immediately after $30 \mathrm{~min}$ with the stop solution provided with the kit. Finally, absorbance or optical density was recorded at $490 \mathrm{~nm}$ using a BioTek $^{\mathrm{TM}}$ Synergy ${ }^{\mathrm{TM}} \mathrm{H} 1$ plate reader, and cell counting was performed using the calibration curve from the standard well plate.

\section{Differentiation Staining}

For differentiation staining, the samples were first washed with DPBS and then fixed in $4 \%$ cold $\left(4^{\circ} \mathrm{C}\right)$ paraformaldehyde for 10 min. Subsequently, the fixed samples were washed 3 times with deionized water. For adipogenic staining, the samples were incubated with $60 \%$ oil red $\mathrm{O}$ working solutions at room temperature in the dark for $30 \mathrm{~min}$. After removal of dyes, the samples were washed with deionized water several times and subsequently mounted for microscopic visualization.

\section{Actin Staining}

The cytoskeleton was stained with the F-actin Visualization Biochem Kit ${ }^{\mathrm{TM}}$ (rhodamine-phalloidin based) following the manufacturer's instructions. Briefly, the samples were first washed with wash buffer and then fixed with the fixatives provided for $10 \mathrm{~min}$. After fixation, the cells were washed 2 times with wash buffer, permeabilized with permeabilization buffer at room temperature for 5 min, followed again by washing twice. Next, F-actin and DAPI were added concurrently and kept for $30 \mathrm{~min}$ in the dark at room temperature. After staining, the samples were washed twice with the same washing buffer and mounted with mounting medium. The stained samples were visualized using the CytoViva hyperspectral microscope system with triple-pass emission filter for DAPI/FITC/Texas red.

\section{RNA Isolation, cDNA Preparation, and qPCR Assays}

RNA was isolated on day 9 of induction with the RNeasy plus mini kit (Qiagen, Germantown, MD, USA). Initially, the samples were washed and incubated with type I collagenase, like the cell viability assay protocol (i.e., CytoTox 96). After incubation, samples were lysed with $350 \mu \mathrm{L}$ buffer RLT plus (Qiagen) and subsequent vortexing (for $2 \mathrm{D}$ ) or homogenization (for 3D) with TissueRuptor II (Qiagen). The rest of the procedure was proceeded according to the manufacturer's protocol. Isolated RNA was quantified spectroscopically with NanoDrop 1000. cDNA was prepared from 500 ng total RNA using the $\mathrm{RT}^{2}$ first-strand kit from Qiagen). Gene microarray analysis was performed with $\mathrm{RT}^{2}$ profiler PCR array for hMSCs (Qiagen), which contains 5 housekeeping genes ( $A C T B, B 2 M, G A P D H, H P R T 1$, and RPLP0), genomic DNA control, reverse transcriptase control, positive PCR control, as well as 84 different genes for expression analysis. All the genes were simultaneously amplified with 96-well Applied Biosystems StepOnePlus ${ }^{\mathrm{TM}}$ real-time PCR (Foster City, CA, USA). The realtime amplifications were observed with StepOnePlus ${ }^{\mathrm{TM}}$ software version 2.3. The baseline and threshold values were set in agreement with Qiagen's instructions for PCR array analysis and kept constant across all samples analyzed. The cycle threshold $\left(\mathrm{C}_{\mathrm{T}}\right)$ value for each gene was extracted from StepOnePlus ${ }^{\mathrm{TM}}$ software to analyze the "fold change" in gene expression using PCR array online data analysis software from Qiagen. The $\mathrm{C}_{\mathrm{T}}$ value cutoff was determined to be 35 . The $2 \mathrm{D}$ adipogenesis model was normalized 


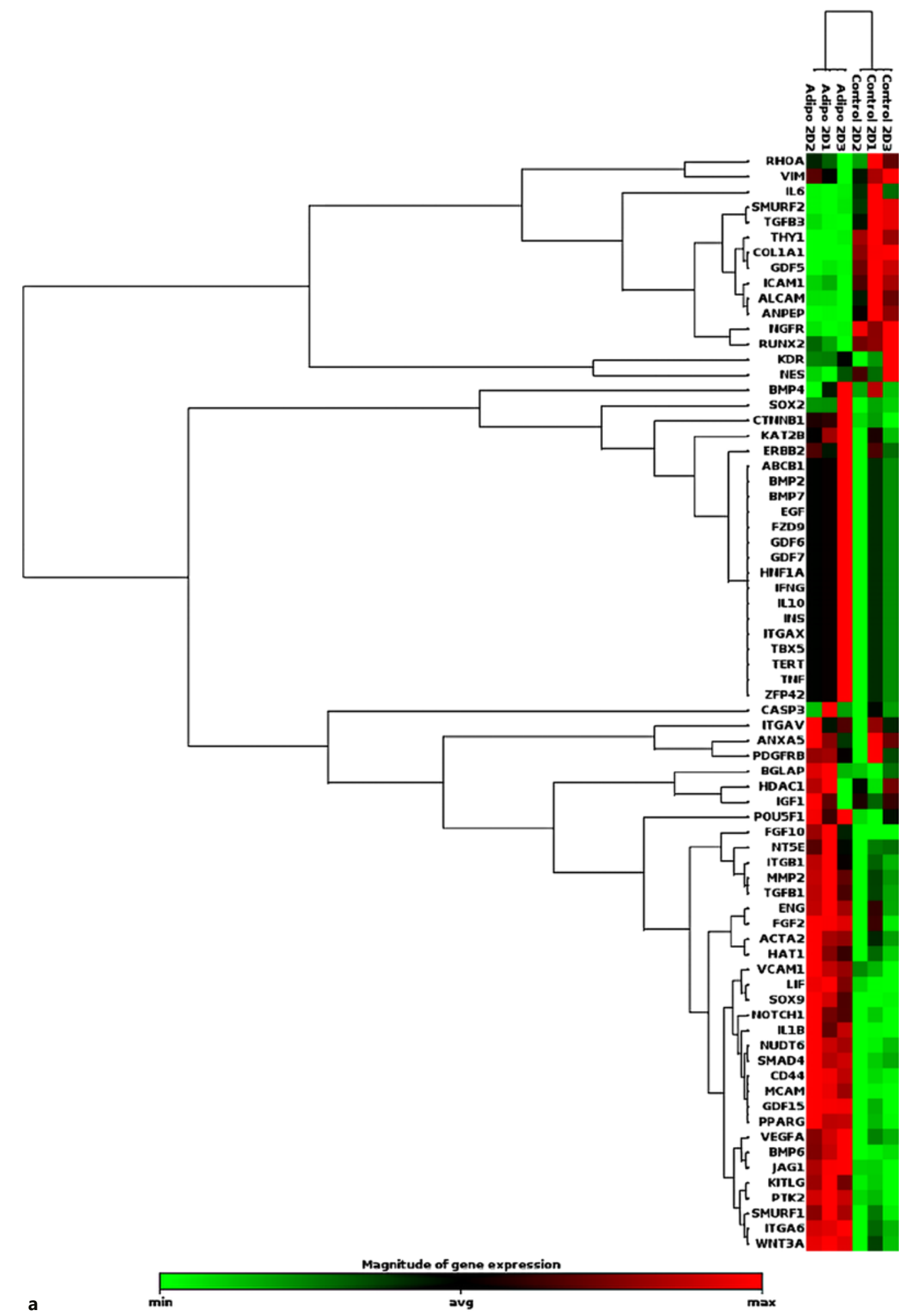

Fig. 1. a Hierarchical cluster analysis showing coregulation of genes from entire datasets across groups or individual samples in $2 \mathrm{D}(\mathbf{a})$ and $3 \mathrm{D}$ adipogenesis (b).

(Figure continued on next page.) 


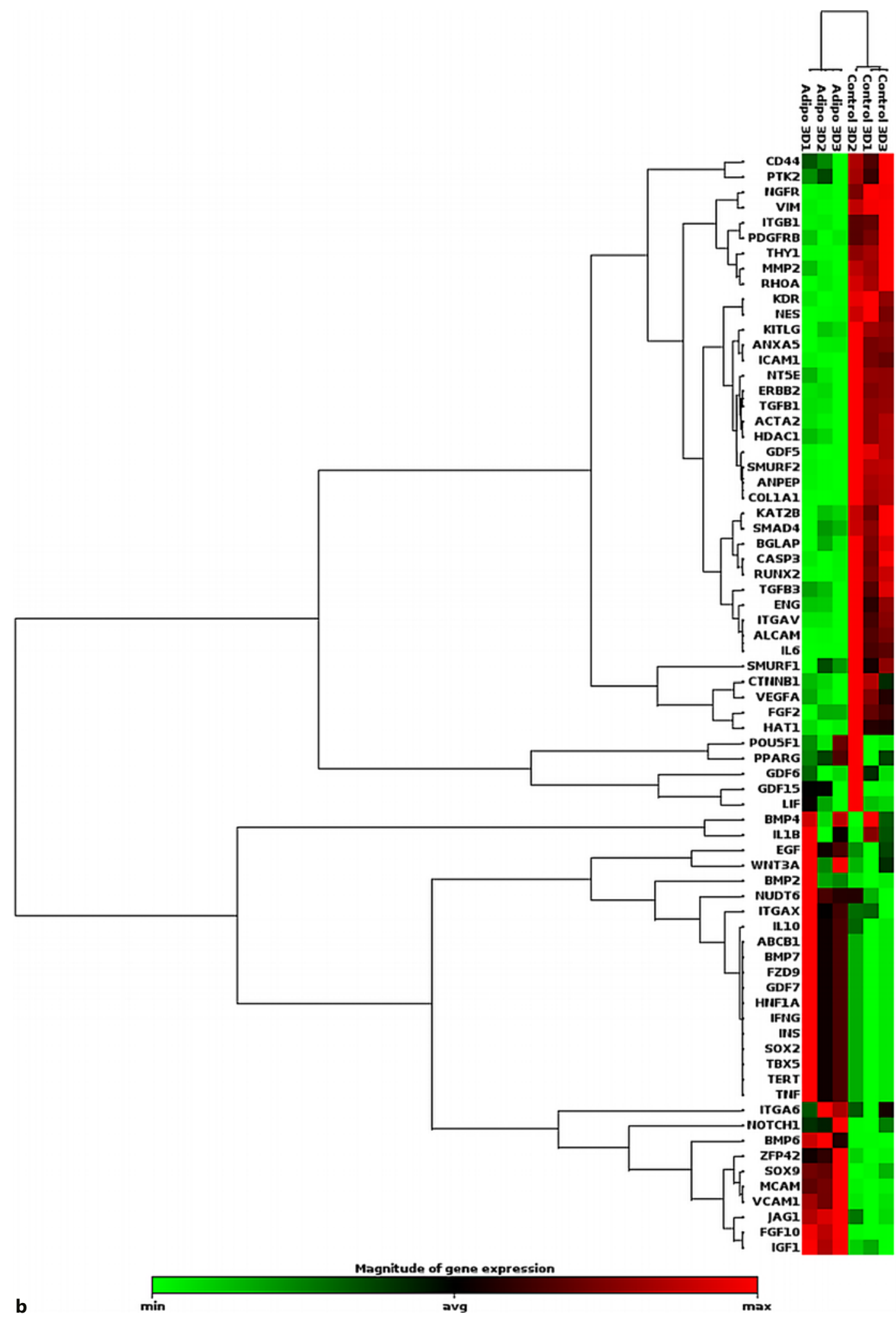




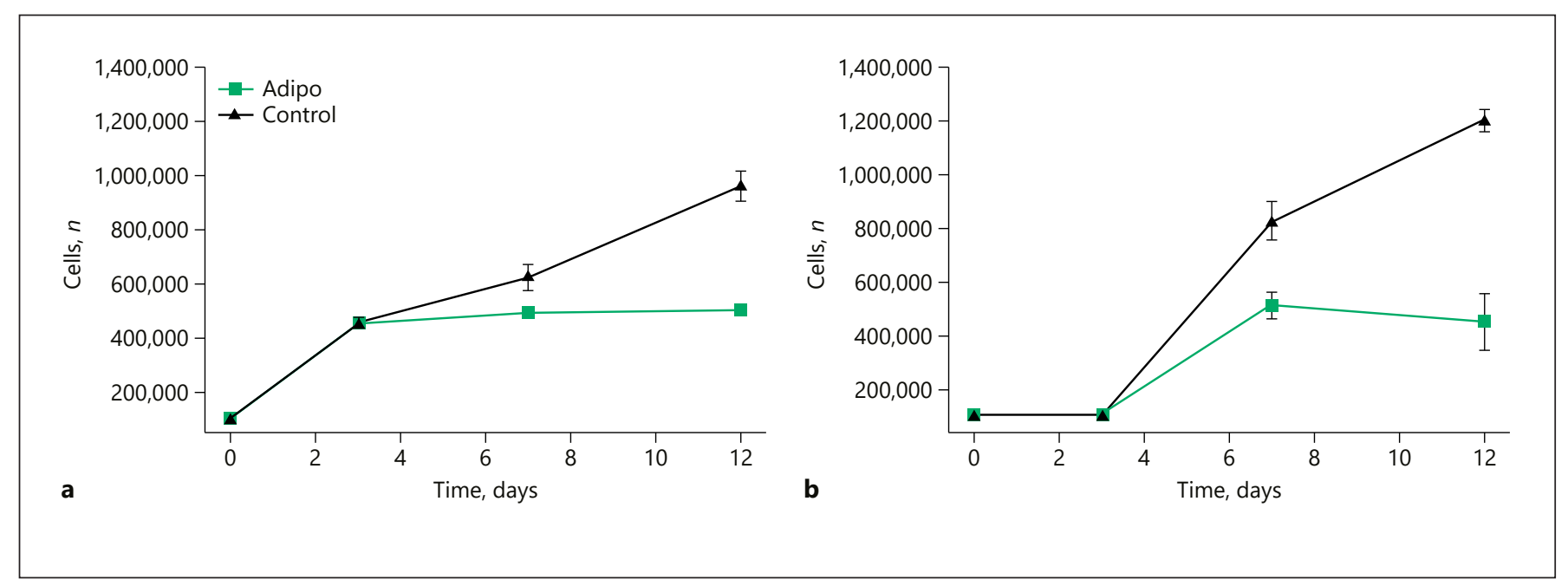

Fig. 2. hASC proliferation in $2 \mathrm{D}$ (a) versus $3 \mathrm{D}(\mathbf{b})$ culture models with respect to time ( $n=6 /$ group for day 3 ; $n=3$ /group for days 7 and 12). Time " 0 " represents the time of seeding with 100,000 cells. The cells were maintained in hMSC growth media for the first 2 days of culture and stimulated with adipogenic media on day 3. Means \pm SD.

against $B 2 M$, whereas the $3 \mathrm{D}$ adipogenesis model was normalized against $R P L P O$ - which provided the $\triangle \mathrm{C}_{\mathrm{T}}$ for each gene of interest $\left(\mathrm{C}_{\mathrm{T} \text { (gene of interest) }}-\mathrm{C}_{\mathrm{T} \text { (housekeeping gene) }}\right)$. Subsequently, $\Delta \Delta \mathrm{C}_{\mathrm{T}}$ was cal-

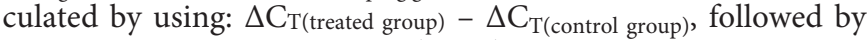
fold change with the formula $2^{(-\Delta \Delta C T)}$. The referred software also provided $p$ values built on Student's $t$ test of the replicate $2^{(-\Delta C T)}$ values of each gene in the control and treatment groups. Additionally, to observe the co-regulation of genes from entire datasets, clustergrams (Fig. 1) were plotted in this software. Fold change " $>1$ " indicates upregulation, whereas " $<1$ " represents downregulation. Overexpressed and underexpressed genes are defined as: $>2$ and $<0.5$-fold change value, respectively.

\section{Enrichment Analysis}

For the differentially expressed genes, the functions and pathways in which they were involved were analyzed using DAVID (Database for Annotation, Visualization and Integrated Discovery) - functional annotation tools [https://david.ncifcrf. gov]. They identify the enriched gene ontology terms and pathways from KEGG, Biocarta, Panther, Reactome, and others to detect the relevant functions associated with a given gene list [Dennis et al., 2003]. Accordingly, for KEGG pathway enrichment analysis using DAVID, the lists of statistically significant $(p<0.05)$ upregulated and downregulated genes were entered, individually, to define the pathways either activated or inhibited, for the in vitro $2 \mathrm{D}$ or $3 \mathrm{D}$ cultures. The thresholds were set as: $p<0.015$, and FDR (false discovery rate) $<0.15$ with default ease of 0.1 .

\section{Statistical Analysis}

The statistical analysis for cell viability and proliferation was done with ANOVA with post hoc Student's $t$ test for pairwise comparisons in JMP Pro13 (SAS, Cary, NC, USA). The statistical analysis for fold change in gene expression was performed with PCR array online data analysis software from Qiagen.

\section{Results and Discussion}

Proliferation, Mitosis, and DifferentiationA Synchronous Process during Adipogenesis

Proliferation in 2D versus 3D hASCs after adipogenic induction was measured at 3 time points (Fig. 2): days 3, 7 , and 12 , with initial time point " 0 " representing the seeding of 100,000 cells (per $1.9 \mathrm{~cm}^{2}$ of $2 \mathrm{D}$ plate or $100 \mu \mathrm{L}$ of total gel volume for 3D encapsulation). The hASCs growth medium was replaced with biochemical adipogenesis induction medium on day 3 of culture. Cells on $2 \mathrm{D}$ substrates showed no change in number following adipogenic induction, whereas the $3 \mathrm{D}$ culture showed initial cell proliferation on day 7. A noticeable feature was the continuous cell proliferation in both $2 \mathrm{D}$ and $3 \mathrm{D}$ control groups measured until day 12 (Fig. 2). Typically, a confluent well $\left(1.9 \mathrm{~cm}^{2}\right)$ in a 24 -well plate consists of a monolayer of about 500,000 MSCs. Human bone marrow-derived MSCs go through contact inhibition growth arrest upon full confluency, while human umbilical cord-derived MSCs and murine adipose tissue-derived stem cells both proliferate forming multilayered cell sheets [Baksh et al., 2007; Jeon et al., 2012]. Combining our hASC results with these data, we can presume that cell-cell contact alone is not enough to halt hASC proliferation.

In general, adipogenic differentiation begins with the proliferation of preconfluent preadipocytes followed by proliferation arrest upon confluency due to contact inhibition [Ruiz-Ojeda et al., 2016]. The confluent preadipocytes 
Table 1. Characteristic features of MSCs/ASCs during adipogenic differentiation

\begin{tabular}{|c|c|}
\hline MSCs/ASCs to adipocytes & Characteristic features \\
\hline MSCs & $\begin{array}{l}\text { - Self-renewal and multilineage differentiation capability } \\
\text { - Expressed genes: POU5F1, SOX2 } \\
\text { - Fibroblasts-like morphology }\end{array}$ \\
\hline Committed preadipocytes & $\begin{array}{l}\text { - Committed to adipocyte lineage differentiation } \\
\text { - Proliferation } \\
\text { - Highlighted genes: Pref-1, SOX9 } \\
\text { - Fibroblast-like morphology }\end{array}$ \\
\hline $\begin{array}{l}\text { Proliferation arrest due to co } \\
\text { Mitotic clonal expansion }\end{array}$ & $\begin{array}{l}\text { ntact inhibition } \\
\text { - Reenter the cell cycle and endure several rounds of mitosis } \\
\text { - Activation of C/EBP } \beta \text { and } C / E B P \delta\end{array}$ \\
\hline Mature adipocytes & $\begin{array}{l}\text { - High expression of adipogenic genes, such as PPARG, } \\
\text { C/EBPa, FABP4, GLUT4 } \\
\text { - Lipid droplets coagulate to form unilocular adipocytes } \\
\text { - Rounded morphology (signet ring) with peripheral nuclei }\end{array}$ \\
\hline
\end{tabular}

then reenter the cell cycle due to hormonal stimulation, going through approximately $2-3$ rounds of mitotic division, known as mitotic clonal expansion (MCE), which leads to the expression of genes related to the adipogenic phenotype (stage-specific characteristic features are shown in Table 1) [Markowitz and Berger, 2012]. However, in contrast to preadipocytes and murine MSCs (C3H10T1/2 cells), 2 studies using a $2 \mathrm{D}$ in vitro model suggested that hMSCs (derived from the bone marrow or adipose tissue) do not undergo MCE during adipogenesis [Entenmann and Hauner, 1996, Qian et al., 2010]. Likewise, in the present study, hASCs in 2D culture show neither proliferation nor MCE, since the cell number was nearly constant over a 9-day period after adipogenic induction (Fig. 2). Along with high cell-cell contact, adipogenic media probably facilitated proliferation arrest of fully confluent 2D cells on day 3 of culture to initiate adipogenesis (Fig. 2). In contrast, encapsulated cells showed initial proliferation upon induction perhaps due to lack of confluency. An interesting aspect to notice is the long-distance interaction among cells in 3D (Fig. 3), which supports the notion that the cells did not encounter density-dependent contact inhibition. Since this study was in- tended to reveal cell viability and proliferation, and not the differentiation stages, further experiments need to be carried out to clarify hASC adipogenesis in the context of in vitro culture dimensions.

\section{Inflammatory Cytokine Expression in a 3D Model}

hMSCs express inflammatory cytokines, including TNF $\alpha$, IL6, IFN $\gamma$, and IL1 $\beta$, that block their differentiation to adipocytes [Okada et al., 2012]. On the other hand, a study conducted by Amable et al. [2014] suggests that hMSC-derived adipocyte-like cells (early adipocytes) do not express proinflammatory cytokines - TNFa, IFN $\gamma$, IL1 $\beta$, or the anti-inflammatory cytokine IL10. Among the 3 tissue sources of MSCs - bone marrow, adipose tissue, and Wharton's jelly - adipose tissue-derived MSCs exhibited the lowest secretion of these cytokines along their differentiation pathway to adipocyte-like cells [Amable et al., 2014]. In our study, using a 2D model, none of these cytokines were found to be differentially expressed, except for IL1B (Table 2; ii). Perhaps, this is due to the overexpression of PPARG and VEGFA, since these genes are known to restrict inflammation and the production of in- 




Fig. 3. Fluorescent images of actin cytoskeleton and nucleus of hASCs undergoing 2D (top row) and 3D adipogenesis (bottom row) following 9-day stimulation with biochemical induction media. Although not quantified, the disrupted actin fiber and rounded nuclei in 2D adipogenesis indicate decreasing cell stiffness [Lee et al., 2009] and initiation of a morphological switch of hASCs from fibroblastic to adipocyte-like cells, whereas 3D induced cells show few bundles of stress fibers; however, the nuclei show nearly rounded morphology, suggesting stress accumulation at basal level. Actin and nuclear staining were performed with phalloidin and DAPI, respectively, and visualized on a CytoViva hyperspectral microscope system. Scale bar, $60 \mu \mathrm{m}$.

flammatory cytokines in adipose tissue [Datta et al., 2017; Fatima et al., 2017]. Conversely, the 3D culture shows significant upregulation of TNFa, IFNG, and IL10 (Table 2; ii). There was no differential expression of PPARG or proinflammatory cytokines in $3 \mathrm{D}$ implying that these cells are still at a very early stage of adipogenesis.

\section{Role of Chromatin Regulators in Adipogenesis}

Epigenetic events play a prominent role during adipogenic differentiation. Chromatin-modifying enzymes, such as histone acetyl transferases (HATs, such as HAT1 and KAT2B) and histone deacetylase (HDACs, such as HDAC1), known to act as transcriptional activators and suppressors during cellular differentiation, respectively. In adipogenesis, HATs increase at the promoter regions of adipogenic genes, while HDAC expression decreases along with the differentiation process [Musri et al., 2010]. Chatterjee et al. [2011], found HDAC1 being expressed in human preadi- pocytes but without significant changes in $\mathrm{mRNA}$ /protein levels during their differentiation to adipocytes; posttranscriptional upregulation of KAT2B was also seen following the expression of C/EBP $\alpha$. Similarly, other studies demonstrated that HDAC1 inhibits PPARG and its target genes, as well as suppresses C/EBP $\beta$ activity [Musri et al., 2010]. To reveal the role of HDACs in MSC differentiation, Lee et al. [2009] treated hMSCs (derived from umbilical cord blood and adipose tissue) with the HDAC inhibitors valproic acid and sodium butyrate the day before lineage-specific induction, which decreased the adipogenic or chondrogenic potency of MSCs. The researchers concluded that since HDAC activity is necessary to induce the preadipocyte stage, the diminished activity of HDACs in MSCs would block their capacity to differentiate into preadipocytes, and consequently, to adipocytes - suggesting that HDAC is essential to maintain MSC self-renewal and pluripotency. The cells in our 2D model seem to agree with 
Table 2. Gene expression in $2 \mathrm{D}$ versus $3 \mathrm{D}$ hASCs with adipogenic biochemical induction

\begin{tabular}{|c|c|c|c|c|c|}
\hline \multirow[t]{2}{*}{ Activities } & \multirow[t]{2}{*}{ Gene symbol } & \multicolumn{2}{|l|}{$2 \mathrm{D}$} & \multicolumn{2}{|l|}{$3 \mathrm{D}$} \\
\hline & & fold change & $p$ value & fold change & $p$ value \\
\hline \multirow{25}{*}{$\begin{array}{l}\text { (i) Signaling molecules/ } \\
\text { growth factors }\end{array}$} & $B M P 2$ & 1.3749 & 0.0867 & 2.8474 & 0.17246 \\
\hline & BMP4 & 1.0775 & 0.81226 & 1.0622 & 0.68767 \\
\hline & BMP6 & 7.9594 & 0.00034 & 11.7724 & 0.00333 \\
\hline & $B M P 7$ & 1.3749 & 0.0867 & 2.2008 & 0.01199 \\
\hline & $T G F B 1$ & 1.7021 & 0.0107 & 0.3304 & 0.00035 \\
\hline & TGFB3 & 0.3915 & 0.01104 & 0.3637 & 0.00283 \\
\hline & GDF5 & 0.1349 & 0.00054 & 0.0074 & $3.4 \mathrm{E}-5$ \\
\hline & GDF6 & 1.3749 & 0.0867 & 0.7086 & 0.27412 \\
\hline & GDF7 & 1.3749 & 0.0867 & 2.2008 & 0.01199 \\
\hline & GDF15 & 11.0834 & $5.6 \mathrm{E}-5$ & 1.0168 & 0.98266 \\
\hline & FZD9 & 1.3749 & 0.0867 & 2.2008 & 0.01199 \\
\hline & CTNNB1 & 1.8579 & 0.01402 & 0.3131 & 0.01837 \\
\hline & NUDT6 & 3.2573 & 0.0002 & 1.5674 & 0.08181 \\
\hline & FGF10 & 23.8293 & 0.01138 & 27.9673 & 0.00002 \\
\hline & $I G F 1$ & 0.9765 & 0.82806 & 3.1333 & 0.00024 \\
\hline & $E G F$ & 1.3749 & 0.0867 & 1.8134 & 0.04167 \\
\hline & $E R B B 2$ & 1.3749 & 0.19086 & 0.1752 & 0.00059 \\
\hline & NGFR & 0.0842 & 0.00025 & 0.0362 & 0.00045 \\
\hline & $J A G 1$ & 2.9697 & 0.00012 & 2.3582 & 0.00089 \\
\hline & NOTCH1 & 5.3864 & 0.00223 & 2.0312 & 0.06677 \\
\hline & SMAD4 & 1.7068 & 0.00022 & 0.5022 & 0.00094 \\
\hline & SMURF1 & 2.4425 & 0.00194 & 0.7053 & 0.02336 \\
\hline & SMURF2 & 0.6687 & 0.01884 & 0.1874 & $3.5 \mathrm{E}-5$ \\
\hline & VEGFA & 2.2632 & 0.00159 & 0.5872 & 0.00663 \\
\hline & $K D R$ & 1.0179 & 0.83219 & 0.114 & 0.00018 \\
\hline \multirow[t]{5}{*}{ (ii) Inflammatory cytokines } & IL6 & 0.1321 & 0.07099 & 0.017 & 0.00249 \\
\hline & $I L 1 B$ & 14.6856 & 0.00069 & 1.0582 & 0.73647 \\
\hline & IL10 & 1.3749 & 0.0867 & 2.0524 & 0.02399 \\
\hline & $T N F \alpha$ & 1.3749 & 0.0867 & 2.2008 & 0.01199 \\
\hline & IFNG & 1.3749 & 0.0867 & 2.2008 & 0.01199 \\
\hline \multirow[t]{3}{*}{ (iii) Chromatin regulators } & $H D A C 1$ & 1.035 & 0.62851 & 0.2587 & 0.00041 \\
\hline & HAT1 & 1.5007 & 0.00985 & 0.4544 & 0.01016 \\
\hline & $K A T 2 B$ & 1.4022 & 0.0699 & 0.2883 & 0.00089 \\
\hline \multirow{20}{*}{$\begin{array}{l}\text { (iv) Cytoskeleton genes and } \\
\text { adhesion molecules }\end{array}$} & RHOA & 0.8584 & 0.22781 & 0.2368 & $5.7 \mathrm{E}-5$ \\
\hline & $V I M$ & 0.9155 & 0.22205 & 0.214 & 0.00002 \\
\hline & NES & 0.5824 & 0.0929 & 0.0676 & 0.00036 \\
\hline & PTK2 & 2.4011 & $8.1 \mathrm{E}-5$ & 0.6857 & 0.01588 \\
\hline & ACTA2 & 1.5721 & 0.00868 & 0.356 & 0.00023 \\
\hline & $A B C B 1$ & 1.3749 & 0.0867 & 2.2008 & 0.01199 \\
\hline & $A L C A M$ & 0.4752 & 0.01371 & 0.1 & 0.00155 \\
\hline & $M C A M$ & 34.5992 & 0.00011 & 14.9113 & 0.00135 \\
\hline & NT5E & 1.2675 & 0.03832 & 0.3579 & 0.00065 \\
\hline & ICAM1 & 0.2562 & 0.00255 & 0.1059 & 0.00115 \\
\hline & VCAM1 & 2.1871 & 0.00094 & 2.098 & 0.00058 \\
\hline & THY1 & 0.2589 & 0.00018 & 0.0422 & 0.00021 \\
\hline & PDGFRB & 1.1027 & 0.45075 & 0.3516 & 0.00203 \\
\hline & KITLG & 2.2038 & 0.00078 & 0.4887 & 0.00045 \\
\hline & CD44 & 3.0398 & 0.00004 & 0.8136 & 0.0101 \\
\hline & $E N G$ & 1.6962 & 0.02641 & 0.5539 & 0.00435 \\
\hline & ITGA6 & 2.7296 & 0.00086 & 1.944 & 0.16102 \\
\hline & ITGAV & 1.094 & 0.33637 & 0.2707 & 0.00205 \\
\hline & ITGAX & 1.3749 & 0.0867 & 1.7092 & 0.0452 \\
\hline & ITGB1 & 1.1723 & 0.01902 & 0.3617 & 0.00183 \\
\hline
\end{tabular}


Table 2 (continued)

\begin{tabular}{|c|c|c|c|c|c|}
\hline \multirow[t]{2}{*}{ Activities } & \multirow[t]{2}{*}{ Gene symbol } & \multicolumn{2}{|l|}{$2 \mathrm{D}$} & \multicolumn{2}{|l|}{$3 \mathrm{D}$} \\
\hline & & fold change & $p$ value & fold change & $p$ value \\
\hline \multirow[t]{8}{*}{ (v) Stemness markers } & INS & 1.3749 & 0.0867 & 2.2008 & 0.01199 \\
\hline & $L I F$ & 8.708 & 0.00043 & 0.9096 & 0.63696 \\
\hline & POU5F1 & 1.6096 & 0.02319 & 1.0147 & 0.9461 \\
\hline & SOX2 & 1.6328 & 0.22095 & 2.2008 & 0.01199 \\
\hline & TERT & 1.3749 & 0.0867 & 2.2008 & 0.01199 \\
\hline & ZFP42 & 1.3749 & 0.0867 & 3.3066 & 0.0107 \\
\hline & FGF2 & 2.0548 & 0.01967 & 0.4506 & 0.00621 \\
\hline & WNT3A & 2.2857 & 0.00192 & 1.7605 & 0.11754 \\
\hline \multirow{5}{*}{$\begin{array}{l}\text { (vi) Key transcriptional } \\
\text { regulators/lineage markers }\end{array}$} & PPARG & 2.8972 & 0.00014 & 0.9952 & 0.9136 \\
\hline & SOX9 & 19.9502 & 0.0012 & 6.6869 & 0.00222 \\
\hline & RUNX2 & 0.4463 & 0.00493 & 0.0795 & 0.00031 \\
\hline & $B G L A P$ & 1.7041 & 0.12131 & 0.2928 & 0.00083 \\
\hline & COL1A1 & 0.0194 & 0.00022 & 0.0029 & $9.8 \mathrm{E}-5$ \\
\hline \multirow[t]{2}{*}{ (vii) Embryonic dev. } & TBX5 & 1.3749 & 0.0867 & 2.2008 & 0.01199 \\
\hline & HNF1A & 1.3749 & 0.0867 & 2.2008 & 0.01199 \\
\hline \multirow[t]{2}{*}{ (viii) Metalloproteinases } & ANPEP & 0.4305 & 0.00564 & 0.1327 & $7.3 \mathrm{E}-5$ \\
\hline & $M M P 2$ & 1.2666 & 0.00865 & 0.471 & 0.00023 \\
\hline \multirow[t]{2}{*}{ (vix) Apoptosis } & ANXA5 & 1.0485 & 0.67918 & 0.2298 & 0.00078 \\
\hline & CASP3 & 1.0644 & 0.5402 & 0.2391 & 0.00073 \\
\hline
\end{tabular}

$n=3$ /group. The $2 \mathrm{D}$ adipogenesis model was normalized against the expression of the housekeeping gene $B 2 M$, whereas $3 \mathrm{D}$ adipogenesis was normalized against the expression of the housekeeping gene RPLPO. Overexpressed, $>2$; underexpressed, $<0.5$. $p<0.05$ was defined as statistically significant.

these findings, where they significantly induced HAT1 (Table 2; iii) and will probably increase the level of KAT2B as adipogenesis progresses. However, all 3 chromatin regulatory genes (i.e., HDAC1, HAT1, and KAT2B) were significantly downregulated in 3D-cultured cells (Table 2; iii). A possible explanation for this behavior is that the hASCs in $3 \mathrm{D}$ progressed to a preadipocyte stage, but the differentiation from preadipocytes to adipocytes is not yet triggered to activate the chromatin regulators HAT1 and KAT2B.

\section{Cytoskeleton Genes and Adhesion Molecules on 2D Hard Substrate}

The cell cytoskeleton, particularly actin cytoskeleton or actin stress fibers, regulates cell mechanical properties. As MSCs proceed to specific lineages, their actin cytoskeleton reorganizes. Using atomic force microscopy indentation, Mathieu and Loboa [2012], measured the Young modulus of hMSCs as $2.5 \mathrm{kPa}$ (spherical) and $3.2 \mathrm{kPa}$ (spread), whereas that of adipocytes was $0.61 \mathrm{kPa}$ (both spherical and spread), suggesting that in contrast to hMSCs, adipocytes do not have a densely packed cyto- skeleton. The major actin cytoskeleton and Rho family small GTPase gene, RHOA, regulates intracellular stress fiber assembly and actin myosin-generated contractility [Tojkander et al., 2012]. Blocking of endogenous RHOA activity promotes MSC differentiation to either adipogenesis or chondrogenesis [Mathieu and Loboa, 2012]. In this study, RHOA expression was significantly downregulated in hASCs grown in 3D culture 9 days after being stimulated with adipocytic induction media, with no significant differences recorded in 2D (Table 2; iv). Two other cytoskeleton-regulatory genes whose differential expression was observed in this study are NES and VIM, encoding the intermediate filament proteins nestin and vimentin, respectively. Nestin is hypoxia responsive [Wong et al., 2014], whereas vimentin maintains cell integrity as well as promotes RHOA or ERK1/2 pathwayregulated osteogenesis [Chen et al., 2016b]. As with RHOA, both NES and VIM expression was significantly downregulated in hASCs grown in $3 \mathrm{D}$ culture following 9-day adipocytic stimulation, with no significant differences measured in 2D culture (Table 2; iv). Since stiffer 
substrates promote activation of cytoskeleton genes, which induce cell stiffness and negatively regulate adipogenesis, underexpression of these genes suggests that the cells in the compliant 3D PuraMatrix endured suitable microenvironments regulating adipocyte-specific cell cytoskeleton properties.

PTK2, a leading cell matrix adhesion gene encoding focal adhesion (FA) kinase, which is a regulator of FAs, is significantly overexpressed in 2D cultures undergoing adipogenesis (Table 2; iv). These FAs are dynamic macromolecular complexes at the cell surface, which bind intracellular cytoskeleton to the extracellular substrate and function as a bidirectional signal transducer [Zebda et al., 2012]. Along with loosely organized actin cytoskeleton, few FAs are expected to form during hASC or MSC adipogenesis, as demonstrated by the lack of differential PTK2 expression in our 3D cultures (Table 2; iv). Likewise, ACTA2 is unexpected in MSCs committed to adipogenesis [Okada et al., 2012], since it encodes smooth muscle $\alpha$-actin and is involved in FA maturation and contractility or force generation [Maeda et al., 2013]. This gene is underexpressed in 3D culture but shows significant upregulation in 2D cultures (Table 2; iv). We speculate that this unexpected behavior in $2 \mathrm{D}$ was due to the extremely stiff (3.5 GPa [Chen et al., 2013]) underlying plastic 2D substrates.

Since integrin-mediated cell adhesion activates FAs, we next analyzed the expression pattern of integrin subunits ITGA6 (laminin receptor), ITGAX (fibrinogen receptor), ITGAV (RGD receptor), and ITGB1 (fibronectin receptor). ITGA6 is significantly overexpressed in $2 \mathrm{D}$ cultures (Table 2; iv). Frith et al. [2012] also showed constant expression of ITGA6 throughout hMSC differentiation to adipocytes. ITGAV and ITGB1, both RGD-binding integrins were significantly underexpressed in 3D cultures, while the fibrinogen receptor, ITGAX, was slightly upregulated (Table 2; iv). Careful consideration of the expression of FAs, cell-matrix, and cell-cell interaction molecules (e.g., ACTA2 and ABCB1) reveals that these genes are more active in $2 \mathrm{D}$ than $3 \mathrm{D}$ cultures. We presume that the differences in behavior between 2D and 3D emerged from the high cellular interaction at the beginning of the induction period (day 3) and stiffness of 2D substrate, chemical and physical properties of the PuraMatrix hydrogel, and/or due to ECM deposition during adipogenic lineage progression.

Expression Pattern of Other Genes in $2 D$ versus $3 D$

Bone morphogenic protein members (BMPs), including BMP2, 4, 6, 7, and 9, can induce MSC commitment and terminal differentiation to either adipocytes or osteoblasts in a mutually exclusive manner [Modica and Wolfrum, 2017; Muruganandan et al., 2009]. In both 2D and $3 \mathrm{D}$ cultures, BMP6, which induces early adipogenesis, is significantly overexpressed (Table 2 ; i), possibly due to the presence of dexamethasone in the biochemical induction media [Diekman et al., 2010]. The 3D culture shows significant upregulation of BMP7 as well (Table 2; i), known to promote hMSC adipogenesis in a high-density micromass culture [Neumann et al., 2007]. However, although there are no detectable changes in BMP4 expression in both culture models (Table 2; i), Bowers and Lane [2007] demonstrated the unique role of BMP4 in inducing murine MSC adipogenesis and determined that endogenous expression of BMP 4 is indispensable to acquire the preadipocyte phenotype [Bowers and Lane, 2008]. GDF5 (BMP14) is a growth factor known for its positive role in adipogenesis. However, in this study, GDF5 is significantly downregulated under both culture conditions (Table 2; i). Another BMP, GDF7 (BMP12), was significantly upregulated only in 3D-cultured cells (Table 2 ; i). GDF7 has been shown to activate tenogenesis in hASCs [Shen et al., 2013], along with moderate activity promoting terminal adipogenesis in murine MSCs (C3H10T1/2 cells) [Kang et al., 2009]. Thus, the expression pattern of some BMPs in our models seem to contradict published results. The selective nature of BMPs probably derives from cell type, tissue source, species, in vitro culture conditions, as well as stage-specific roles during lineage development.

This study shows differential expression of IGF1 in 3D cells (Table 2; i), which promotes preadipocyte proliferation [Harrington et al., 2007]. In an in vivo study, IGF1 was found to inhibit $\mathrm{Wnt} / \beta$-catenin signaling via Axin2/ PPARG pathway activation, showing selection bias for adipocyte progenitors [Hu et al., 2015]. Likewise, EGF is significantly upregulated only in 3D (Table 2; i), which positively regulates mitotic nuclear division [Harrington et al., 2007], and it is known to inhibit triglyceride lipid accumulation in 3T3-L1 cell lines [Adachi et al., 1994]. If these genes play a similar role in hASCs, then it also supports that the cells in $3 \mathrm{D}$ are in preliminary stages of adipogenesis. On the other hand, SMAD-specific E3 ubiquitin ligase 1 (SMURF1) is differentially expressed in 2D cells (Table 2; i), known to prevent degradation of orphan nuclear receptor Nur77, which in turn fosters earlystage adipocyte differentiation by stimulating MCE in 3T3-L1 cells [Fumoto et al., 2007; Watanabe et al., 2015]. However, we did not find any published evidence on the role SMURF1 plays during MSC/ASC adipogenesis. We 
Table 3. Stage-specific gene expression during adipogenic differentiation of MSCs/ASCs

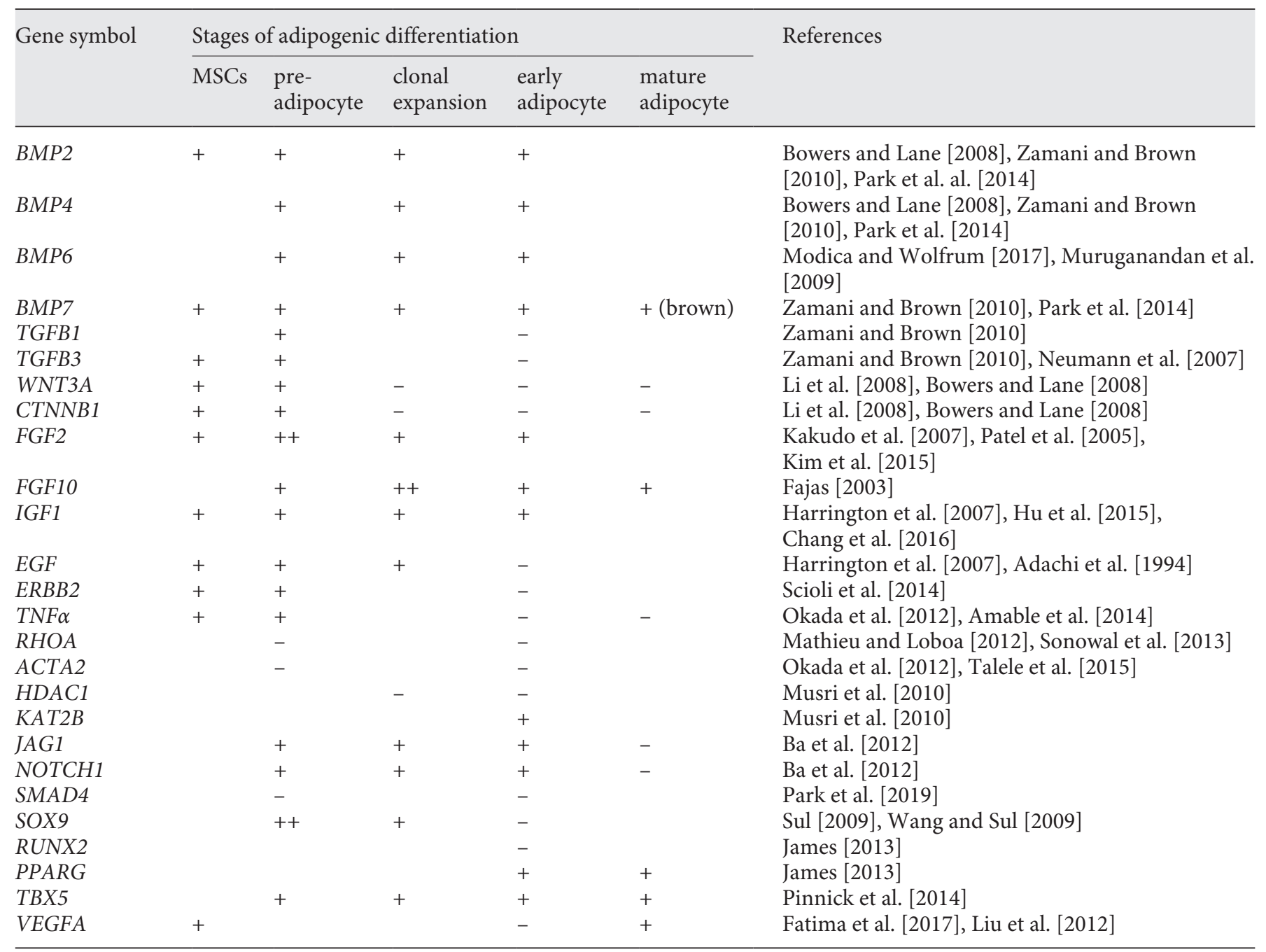

Here, MSC adipogenic differentiation has been categorized into 4 stages: MSCs to preadipocytes, mitotic clonal expansion, early adipocytes, and matured adipocytes. The genes showing stage-specific positive or negative regulatory roles during MSC differentiation to adipocytes are, therefore, expected to either express or suppress the respective stages to foster adipogenesis. The expression pattern of some of the genes are correlated with the cell source, MSCs types, and in vitro culture conditions.

also observed significant upregulation of JAG1 and NOTCH1 under both culture conditions (Table 2; i). Constitutively active NOTCH1 is reported to promote early adipocytes, failing to form matured adipocytes in the latter [Kang et al., 2009]. JAG1-mediated NOTCH signaling activation has been shown to promote early adipogenesis in mouse ASCs by inducing enhanced expression of PPARG [Kang et al., 2009]. The upregulation of these genes in our study suggests a proadipogenic environment in both 2D and 3D culture models. However, the responses of $\mathrm{NOTCH}$ signaling on adipogenesis may depend on the cell type, e.g., in human bone marrow- derived MSCs, inhibition of Notch signaling promoted adipocytic differentiation [Garcés et al., 1997]. The authors found downregulation of NOTCH1 and no change in JAG1 expression during human bone marrow-derived MSC adipogenesis.

ASCs secrete various angiogenic factors (e.g., VEGFA, FGF2, and MMPs); some of them are transcriptionally regulated by PPARG during adipogenesis. Overexpression of VEGFA suppresses adipogenic differentiation of MSCs, independent of VEGFR1- and VEGFR2-mediated signaling mechanisms [Liu et al., 2012]. However, in mature adipocytes, VEGFA activity 
is necessary to promote angiogenesis and to limit adipocyte hypertrophy [Fatima et al., 2017]. In this study, VEGFA is significantly upregulated only in 2D systems (Table $2 ; \mathrm{i}$ ). We assume that since 2D cells are likely adipogenic committed by upregulating PPARG, they thus activate VEGFA to regulate angiogenesis and adipose tissue development.

Similar to VEGFA, MMP2 is an important regulator of angiogenesis and matrix remodeling during adipogenesis in preadipocytes [Mannelloet al., 2006]. Besides MMP2, another protease, ANPEP, takes part in ECM remodeling through an unknown mechanism during MSC adipogenesis. The 3D culture shows significant downregulation of both metalloproteinases, yet in 2D systems MMP2 is significantly upregulated (Table 2; viii), possibly due to progression in the differentiation process.

The apoptosis-related genes ANXA5 and CASP3 are underexpressed in 3D systems (Table 2; vix), while no significant changes in 2D systems are seen (Table 2; vix), suggesting a lack of cytotoxicity or initiation of apoptosis in either model. Embryonic developmental genes HNF1A and TBX5 are significantly upregulated only in $3 \mathrm{D}$ systems (Table 2 ; vii). TBX5 is known to regulate preadipocyte proliferation as well as differentiation to mature adipocytes. TBX5 gene knockdown by shRNA in abdominal subcutaneous adipose tissue-derived preadipocytes exhibited 1.5 -fold reduction in proliferation in comparison with nontargeted controls, and inhibition of proadipocytic transcription factor $\mathrm{C} / \mathrm{EBP} \alpha$ and $\mathrm{PPARG}$, as well as significant reduction in functional genes (FABP4, FASN, PLINI, and ADIPOQ) [Pinnick et al., 2014]. Therefore, the above data suggest that the gene expression pattern during MSC adipogenesis is different in $3 \mathrm{D}$ compared to $2 \mathrm{D}$ cell cultures.

\section{Adipogenic Lineage Progression in $2 D$ versus $3 D$ Cultures}

To compare adipogenic lineage progression, we first looked at the expression of 2 transcription factors PPARG and RUNX2. The former is the master transcription factor regulating early adipogenesis. Generally, all the preadipogenic factors or signaling pathways converge on the PPARG pathway to induce adipogenesis [James, 2013]. On the other hand, RUNX2 is the primary transcription factor for osteogenic differentiation and known as a PPARG antagonist [Ge et al., 2016], with its suppression promoting MSC adipogenic commitment [James, 2013]. Accordingly, we observed downregulation of RUNX2 under both culture conditions, but PPARG was

$2 \mathrm{D}$ versus $3 \mathrm{D}$ Adipogenic Gene

Expression differentially expressed only in 2D, with no changes seen in 3D (Table 2; vi). Since PPARG is activated during the preadipocyte to adipocyte transition [MacDougald and Lane, 1995], its overexpression demonstrates the start of adipogenesis in 2D cultures.

Regarding the progression in 3D, 2 highly expressed genes are of importance: transcription factor SOX9, induced by the preadipocyte marker Pref- 1 in preadipocytes, and FGF10, whose expression peaks during clonal expansion and is a potent inducer of the adipogenic transcription factor C/EBP $\beta$ [Fajas, 2003]. Overexpression of both genes in conjunction with the overall expression pattern (according to Table 3) suggests that the 3D cells are either at the proliferating preadipocyte or at the clonal expansion stage.

Although we considered the clonal expansion stage here, our previous discussion warrants additional experimentation to analyze whether MCE really exists during MSC/ASC differentiation to adipocytes.

\section{Pathway Functional Enrichment in $2 D$ versus $3 D$ Adipogenesis}

The only meaningful pathway found to be activated in $2 \mathrm{D}$ adipogenesis is the one regulating pluripotency of stem cells, whereas downregulated genes in $2 \mathrm{D}$ did not yield any relevant pathway (Table 4 ). In $3 \mathrm{D}$, the activated signaling pathway is that in which the upregulated gene for TGF $\beta$ is involved, which plays an inhibitory role in adipogenic differentiation but is crucial to expand preadipocytes. Cells differentiating from preadipocytes to adipocytes downregulate the expression of TGF $\beta$ receptors [Choy et al., 2000]. Interestingly, the TGF $\beta$ pathway has also been found to be enriched with downregulated genes (Fig. 4a) in 3D systems. TGF $\beta$ plays dual roles in manipulating MSC lineage specification to adipogenesis and osteogenesis [Chen et al., 2016a]. By binding to their type I and type II serine/threonine kinase cell surface receptors, TGF $\beta$ activates canonical Smad-dependent signaling pathways and noncanonical Smad-independent pathways, such as the p38 mitogen-activated protein kinase (MAPK) pathway. Upon TGF $\beta$ activation, expression of Runx2 or PPARG can either be regulated by the Smad or p38 MAPK pathway [Chen et al., 2016a], where both pathways favor osteogenesis and inhibit adipogenesis. As depicted in Figure 4a, Smad and MAPK both have been affected by the 3D-downregulated genes. The other pathways inhibited in $3 \mathrm{D}$ are: PI3K-AKT, RAP1, and FA. Generally, PI3K-AKT (Fig. 4b) is downstream of integrin signaling regulating MSC differentiation to early osteogenesis or adipogenesis in a context- or time-dependent 
Table 4. Pathway enrichment analysis for statistically significantly up- and downregulated genes in $2 \mathrm{D}$ versus $3 \mathrm{D}$ adipogenesis

\begin{tabular}{|c|c|c|}
\hline Pathways & Candidate genes & $p$ value \\
\hline \multicolumn{3}{|l|}{$2 \mathrm{D}$ adipogenesis } \\
\hline \multicolumn{3}{|l|}{ Upregulated genes } \\
\hline pluripotency of stem cells & LIF, SMAD4, WNT3A, CTNNB1, POU5F1, FGF2 & \\
\hline Downregulated genes & - & \\
\hline TGF $\beta$ signaling pathway & BMP6, BMP7, GDF7, IFNG, TNF & $1.1 \times 10^{-4}$ \\
\hline \multicolumn{3}{|l|}{ Downregulated genes } \\
\hline TGF $\beta$ signaling pathway & SMAD4, SMURF1, SMURF2, GDF5, RHOA, TGFB1, TGFB3 & $4.8 \times 10^{-6}$ \\
\hline PI3K-AKT signaling pathway & KITLG, COL1A1, FGF2, ITGAV, ITGB1, IL6, KDR, NGFR, PDGFRB, PTK2, VEGFA & $9.1 \times 10^{-6}$ \\
\hline Focal adhesion & CTNNB1, COL1A1, ERBB2, ITGAV, ITGB1, KDR, PDGFRB, PTK2, RHOA, VEGFA & $9.8 \times 10^{-7}$ \\
\hline RAP1 signaling pathway & KITLG, CTNNB1, FGF2, ITGB1, KDR, NGFR, PDGFRB, RHOA, VEGFA & $1.2 \times 10^{-5}$ \\
\hline
\end{tabular}

manner [Song et al., 2017]. During adipogenic differentiation, the mediators of the PI3K-AKT pathway and its downstream effectors mTOR, p27, FOXO1, and p70S6K are increased [Ramazzotti et al., 2019]. The FA pathway (Fig. 4d) favors osteogenesis over adipogenesis. Inhibition of the FA pathway suggests that the expression of genes regulating adipocyte-like cell mechanical properties is consistent with the differential gene expression in 3D systems. RAP1 (Fig. 4c), a small GTPase, controls cell adhesion and junction formation. Numerous junction proteins, as well as proteins regulating actin cytoskeleton, act as effectors of RAP1 signaling [Kooistra et al., 2007]. Inhibition of RAP1 or loss of adhesion commonly incurs cell cycle arrests in the G1 phase [Schwartz and Assoian, 2001]. According to Marcon et al. [2019], upon adipogenic induction, hASCs show G1 phase cell cycle arrest consistent with decreased proliferation during early adipogenesis. Therefore, in line with our estimation based on Table 3, the 3D pathways reinforce cell lineage progression in the early stage and probably on the verge of adipogenic differentiation.

\section{Aberrant Behavior of Gene Expression in $2 D$}

During $2 \mathrm{D}$ adipogenesis, there is significant upregulation of TGFB1, WNT3A, and CTNNB1 ( $\beta$-catenin; Table 2; i), an unexpected finding during this type of differentiation. For instance, TGF $\beta$ is a pleiotropic cytokine known to be required for preadipocyte expansion while simultaneously inhibiting preadipocyte to adipocyte transition by suppressing $\mathrm{C} / \mathrm{EBP} \alpha$ and PPARG both in vitro and in vivo [Choy et al., 2000]. However, similar to our 2D results, Amable et al. [2014] found enhanced TGFB1 ex- pression in adipocyte-like cells induced from $2 \mathrm{D}$-cultured bone marrow-, adipose tissue-, or Wharton jelly-derived MSCs. Interestingly, both TGFB1 and TGFB3 are significantly downregulated in our 3D cultures (Table 2; i), similar to WNT3A and CTNNB1, the primary constituents of the Wnt/ $\beta$-catenin pathway, which inhibits the adipogenic potential of MSCs suppressing key transcripts of adipogenesis (i.e., C/EBPa and PPARG) [Li et al., 2008].

However, the expression level of these genes is either close to or below the cutoff value set for differentially expressed genes. Perhaps, the level of expression of these genes is decreasing with progressing PPARG expression, or the mRNA levels of these genes are not sufficient to allow the synthesis of functional proteins that can interact with the adipocyte-regulatory genes, which would explain the simultaneous expression of PPARG and its inhibitors TGFB1, WNT3A, and CTNNB1. Furthermore, a pleiotropic cytokine, GDF15, is highly expressed in 2D adipogenesis (Table $2 ; \mathrm{i}$ ), which is known to accelerate oxidation along with lipolysis in matured adipocytes [Lee et al., 2017]. Curiously, we noticed the differential expression of this gene during hASC differentiation to trilineage pathways, i.e., adipogenesis, osteogenesis, and chondrogenesis ( $n=3$ /group), only in 2D cultures (Table 5$)$. It would be interesting to see how the immune microenvironment and cross talk among cytokines in hASC differentiation pathways is regulated in $2 \mathrm{D}$ cultures.

\section{Role of SOX9 in MSC Adipogenesis}

SOX9 is the key determinant of chondrogenesis and is involved in maintaining diverse cell functions, such as those related to stem cells, differentiation, and several dis- 


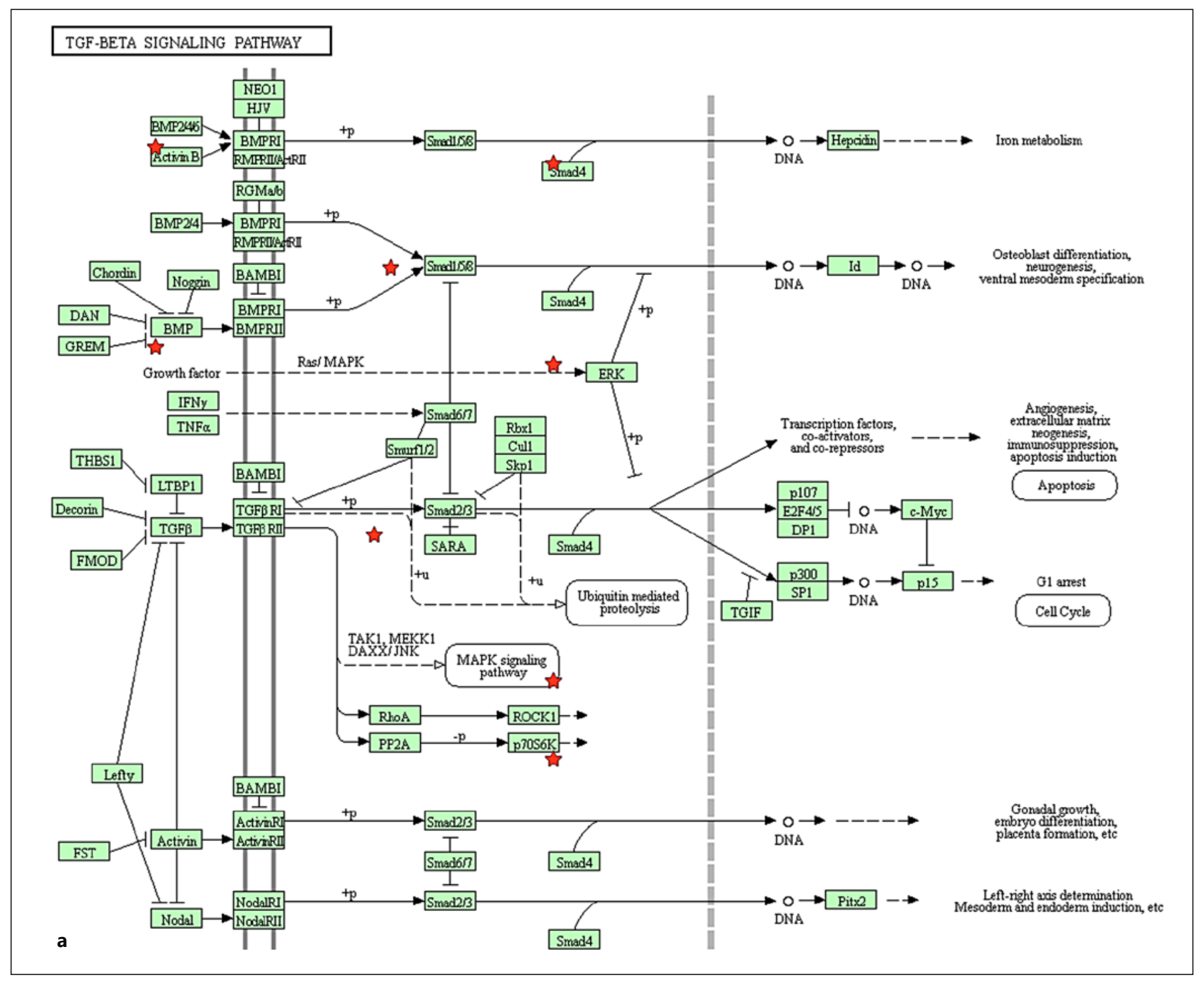

Fig. 4. a TGF $\beta$ signaling pathway (a), PI3K-AKT signaling pathway (b), RAP1 signaling pathway (c) and focal adhesion pathway $(\mathbf{d})$ enriched with 3D downregulated genes (from the KEGG PATHWAY Database; https:// www.genome.jp/kegg/pathway.html).

(Figure continued on next page.)

eases [Jo et al., 2014]. In adipogenesis, however, the preadipocyte marker Pref-1 inhibits adipogenesis via SOX9 gene expression, which binds to the promoter region of $\mathrm{C} /$ $\mathrm{EBP} \beta$ and $\mathrm{C} / \mathrm{EBP} \delta$, suppressing their expression. Since the expression of these 2 transcription factors is essential for sequential activation of PPARG and $\mathrm{C} / \mathrm{EBP} \alpha$, cells remain at the preadipocyte stage, suppressing their differentiation to adipocytes. Basically, by inducing SOX9, Pref-1 promotes MSC commitment to chondrogenesis and inhibits adipogenesis. Therefore, it would be expected that SOX9 downregulation would induce key adipogenic markers [Sul, 2009; Wang and Sul, 2009]. Although in the present study 3D culture of hASCs seems to agree with this, cells grown in 2D do not (Table 2; vi). In a study in rat MSCs grown in 2D, Stöckl et al. [2013] showed some contrasting results, where they observed that silencing SOX9 actually hinders C/EBP $\beta$ protein expression by destabilizing $\mathrm{C} /$ EBP $\beta$ mRNA. To perceive how this aspect influences adipogenesis, the authors analyzed adipogenic marker expression for 21 days after biochemical induction. As a consequence of reduced $\mathrm{C} / \mathrm{EBP} \beta$, they noticed significant reduction in PPARG, SREBF1, and FASN on day 7 and LPL 14 days following SOX9 knockdown in MSCs. By day 21, the mRNA levels of these genes returned to the control levels. 




(Figure continued on next page.)

Since the authors used a 2D culture, it is not clear whether culture dimensionality has any effect on this behavior, and how cells in $3 \mathrm{D}$ culture behave regarding SOX9 expression when they enter adipogenesis. A time-dependent analysis of adipogenesis in 2D and 3D cultures would reveal SOX9 gene expression patterns during MSC/hASC adipogenesis.

\section{Concerns with the 3D Adipogenesis Model}

A concern with $3 \mathrm{D}$ cultures is the lack of expression of the key adipogenic marker PPARG, which is expected to be highly expressed after day 9 of induction. To be noted, for adipogenic gene expression, the biochemical induction medium was revised with 1-ascorbate-2-phosphate (ascorbic acid derivative, AA) and increasing concentrations of dexamethasone (from $10^{-7}$ to $10^{-6} \mathrm{M}$ ). AA is known to stimulate cell proliferation either directly by modulating proliferation-related signaling pathways or indirectly by collagen matrix deposition [Brigelius-Flohé and Flohé, 1996; Zhang et al., 2016]. It has already been established that dexamethasone works cooperatively with AA to promote MSC osteogenesis, which gives rise to the question of whether this combination directed cells to osteogenesis. However, using the same formulation, our gene expression data clearly support that $2 \mathrm{D}$ cells are early adipocytes and 3D cells are approaching the adipocyte lineage. It is known that higher AA $(150-250 \mu \mathrm{M})$ and lower dexamethasone concentrations $(5-10 \mathrm{nM})$ promote hASC proliferation, osteogenesis via Runx2 upregulation, and high ALP activity. Conversely, high dexamethasone concentrations ( $>10 \mathrm{nM}$ ) favor adipogenesis over osteogenesis in MSCs. Furthermore, in 3T3-L1 cells, AA was shown to promote adipogenesis via ColVI upregulation. Another study showed that AA promotes MSC proliferation in a concentration-dependent manner without altering their differentiation potential, and addition of 50-500 $\mu \mathrm{M}$ AA as part of the conventional adipogenic 

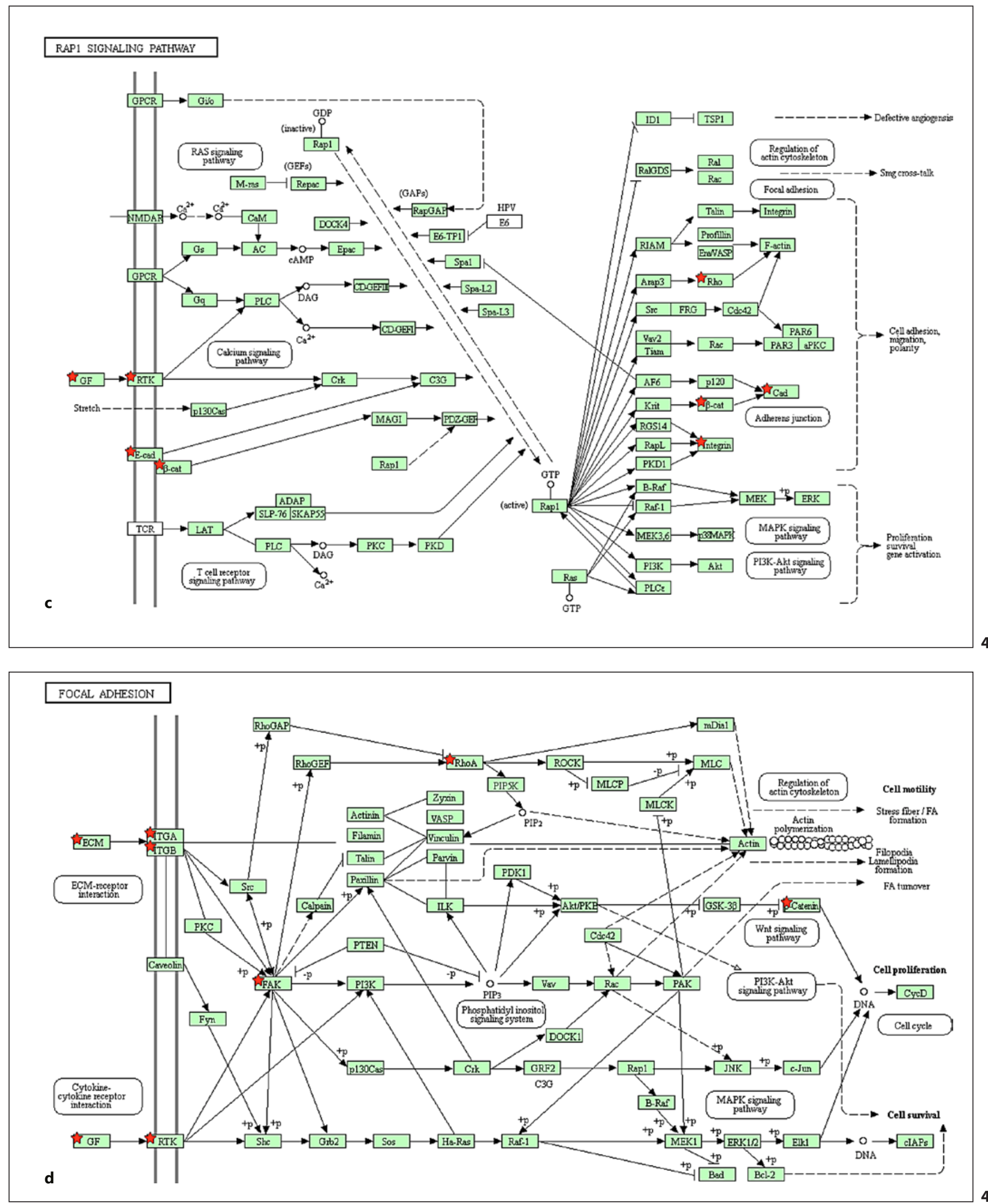

$2 \mathrm{D}$ versus 3D Adipogenic Gene

Cells Tissues Organs 2019;208:113-133 Expression 
Table 5. Expression of GDF15 during hASC differentiation to trilineages

\begin{tabular}{|c|c|c|c|c|}
\hline \multirow{3}{*}{$\begin{array}{l}\text { Induced } \\
\text { lineages }\end{array}$} & \multicolumn{4}{|c|}{ Expression level of GDF15 } \\
\hline & \multicolumn{2}{|c|}{$2 \mathrm{D}$ culture } & \multicolumn{2}{|c|}{$3 \mathrm{D}$ culture } \\
\hline & $\begin{array}{l}\text { fold } \\
\text { change }\end{array}$ & $p$ value & $\begin{array}{l}\text { fold } \\
\text { change }\end{array}$ & $p$ value \\
\hline Adipogenesis & 11.083 & $5.6 \times 10^{-5}$ & 1.0168 & 0.982660 \\
\hline Osteogenesis & 4.1487 & 0.025527 & 0.5562 & 0.216055 \\
\hline Chondrogenesis & 4.1795 & 0.017033 & 0.9249 & 0.614270 \\
\hline
\end{tabular}

cocktail greatly enhanced BMSC adipogenesis compared to the addition of $0-5 \mu \mathrm{M}$. In this experiment, we intended to use the same initial seeding density and time of induction for $2 \mathrm{D}$ and $3 \mathrm{D}$; however, we observed very low cell proliferation in $3 \mathrm{D}$ (Fig. 2) after being stimulated with induction media. For this reason, AA $(250 \mu \mathrm{M})$ was added to promote cell proliferation after biochemical adipogenic induction. As expected, we observed a higher cell proliferation for both culture systems, with a longer effect in $3 \mathrm{D}$ (since, in contrast to $2 \mathrm{D}$, percent cell confluence was very low during the addition of induction media), which might explain their late adipogenic activity, as we mentioned earlier, with growth arrest being a prerequisite to actuate the adipocytic machinery.

Since the PuraMatrix hydrogel is composed of interweaving nanofibers $10-20 \mathrm{~nm}$ in diameter [Zhang et al., 1993, 1995] with interior pores of 50-200 $\mathrm{nm}$ [Kisiday et al., 2002], our initial assumption was that the small pore sizes acted as a barrier for the micron-sized hASCs to change their phenotypes inside these nanopores for intracellular lipid accumulation, resulting in late activation of adipogenesis in 3D. However, the biochemical induction media devoid of AA show lipid accumulation 9 days after induction at the same time as $2 \mathrm{D}$ (Fig. 5), suggesting that the smaller pore sizes may not be an inhibitory factor for the early cascade of adipogenesis, but AA is perhaps responsible for the delay in $3 \mathrm{D}$ adipogenesis.

Matrix Mechanics, Initial Cell Seeding Density, and Biochemical Factors: Mutual Role in Adipogenesis

In the pioneering research work of McBeath et al. [2004], it was shown that irrespective of cell proliferation, hMSCs cultured at low seeding density (1,000 cells/ $\mathrm{cm}^{2}$ ) could not accumulate cytoplasmic lipid droplets when exposed to adipogenic induction medium, which indicates that cell-cell interaction during the first several hours following biochemical stimulation involves MSC commitment to specific cell lineages. In addition, high cell density enhances cell-cell communication, paracrine signaling, as well as a reduction in RHOA activity, which are key characteristics of MSCs undergoing adipogenesis [McBeath et al., 2004]. Accordingly, we found earlier intracellular lipid formation on highly confluent $2 \mathrm{D}$ substrates, although with a stiffness of 3.5 $\mathrm{GPa}$, which is far greater than the stiffness expected for inducing MSC adipogenesis. The native adipose tissue stiffness is $2-6 \mathrm{kPa}$ [Akhmanova et al., 2015] and according to in vitro research demonstrations, matrices with stiffness in this range stimulate MSC adipogenesis. However, this is probably attributable to the high cell density during induction, for which reason, instead of the stiff plastic substrate, cells in 2D sensed the softness of surrounding adherent cells [Wells, 2008]. On the other hand, the $0.5 \%$ PuraMatrix peptide concentration that we used in this study provides the required $2.5-\mathrm{kPa}$ stiffness level [Chen et al., 2013]; however, it was not enough to induce early and enhanced adipogenesis. Therefore, optimal cell density, biochemical induction composition, and matrix mechanics, all play with dimensionality to constitute the cellular microenvironment necessary to determine the fate of MSCs and ASCs.

\section{Conclusion}

Our research findings support a gene expression profile of MSC differentiation during adipogenesis, which varies as a function of culture dimensionality and presence of associated factors regulating the microenvironment, such as seeding density and biochemical induction factors. Certainly, there are some similarities in gene expression, as both culture systems comprise the same cell lines, and nearly all signaling pathways converge in the PPARG pathway to induce adipogenesis. However, the focal point from this experiment is that the expression of genes regulating adipocyte-like cell mechanical properties is more consistent in $3 \mathrm{D}$ culture.

The aim of this project was to identify variations in $2 \mathrm{D}$ versus $3 \mathrm{D}$ gene expression, hence the donor variation was disregarded, although including this factor could have broadened the perspectives of this project as ASC/MSC behavior strongly correlates with donor type. A time-dependent gene expression study, which enables the evaluation of gene expression patterns and signaling pathways involved in different stages of hASC adipogenesis, would have been more informative. Moreover, lack of published gene expression data using adult progenitor cells made a comparison of cell expression behavior difficult, since 


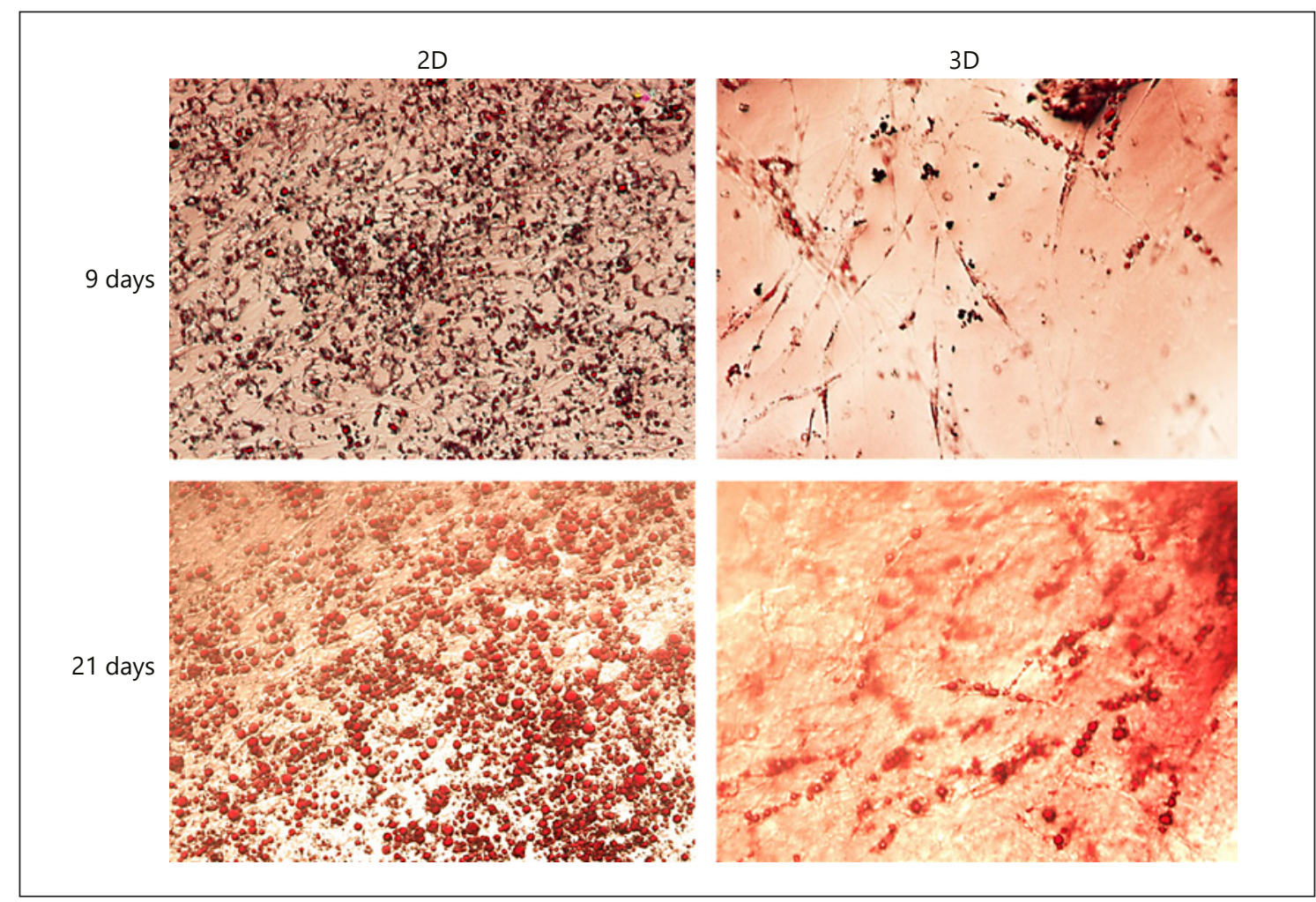

Fig. 5. Oil red O staining images of adipocyte-like cells to visualize the lipid content induced in $2 \mathrm{D}$ - and $3 \mathrm{D}$ cultured hASCs (adipogenic medium formulation: $10^{-7} \mathrm{M}$ dexamethasone, $0.5 \mathrm{mM}$ IBMX, $60 \mu \mathrm{M}$ indomethacin, and $10 \mu \mathrm{g} / \mathrm{mL}$ insulin). Original magnification was $\times 100$.

most in vitro adipogenesis differentiation biology studies are based on preadipocytes. According to Ruiz-Qjeda et al. [2016], over a period of 5 years (2011-2015), nearly a third of research studies on adipogenesis mechanisms and obesity-associated treatment involves only the 3T3L1 cell line. ASCs, due to their vascular location in adipose tissue, are easily accessible for therapeutic applications. Thiazolidinediones have been proven to soothe symptoms of the metabolic syndrome partly by stimulating the ASCs to proliferate and differentiate into new insulin-sensitive small adipocytes [Berry et al., 2013]. Due to the promising potency of ASCs in therapeutics and regenerative medicine, its molecular mechanisms during adipogenesis must be fully revealed in context of culture microenvironments.

\section{Statement of Ethics}

This study was based on the use of ASCs acquired from a commercial source (Lonza, Walkersville, MD, USA). None of the experiments involved the use of animals or clinical subjects.

\section{Disclosure Statement}

The authors have no conflicts of interest to declare.

\section{Funding Sources}

The study was not financially supported.

\section{Author Contributions}

F.T. Zohora: collection and/or assembly of data, data analysis and interpretation, and manuscript writing; A.I. Aldebs: collection and/or assembly of data, data analysis, and interpretation; $N$. Nosoudi: assembly of data, data analysis and interpretation, and manuscript writing; S.P. Singh: conception and design of the work, and data interpretation; and J.E. Ramirez-Vick: conception and design, data analysis and interpretation, manuscript writing, and final approval of manuscript. 


\section{References}

Adachi H, Kurachi H, Homma H, Adachi K, Imai $\mathrm{T}$, Morishige $\mathrm{K}$, et al. Epidermal growth factor promotes adipogenesis of 3T3-L1 cell in vitro. Endocrinology. 1994 Nov;135(5):1824-30.

Akhmanova M, Osidak E, Domogatsky S, Rodin S, Domogatskaya A. Physical, spatial, and molecular aspects of extracellular matrix of in vivo niches and artificial scaffolds relevant to stem cells research. Stem Cells Int. 2015;2015:167025.

Amable PR, Teixeira MV, Carias RB, Granjeiro JM, Borojevic R. Gene expression and protein secretion during human mesenchymal cell differentiation into adipogenic cells. BMC Cell Biol. 2014 Dec;15(1):46.

Ba K, Yang X, Wu L, Wei X, Fu N, Fu Y, et al. Jagged-1-mediated activation of notch signalling induces adipogenesis of adipose-derived stem cells. Cell Prolif. 2012 Dec;45(6):538-44.

Baksh D, Yao R, Tuan RS. Comparison of proliferative and multilineage differentiation potential of human mesenchymal stem cells derived from umbilical cord and bone marrow. Stem Cells. 2007 Jun;25(6):1384-92.

Baptista LS, da Silva KR, da Pedrosa CS, Claudioda-Silva C, Carneiro JR, Aniceto M, et al. Adipose tissue of control and ex-obese patients exhibit differences in blood vessel content and resident mesenchymal stem cell population. Obes Surg. 2009 Sep;19(9):1304-12.

Berry DC, Stenesen D, Zeve D, Graff JM. The developmental origins of adipose tissue. Development. 2013 Oct;140(19):3939-49.

Bowers RR, Lane MD. A role for bone morphogenetic protein-4 in adipocyte development. Cell Cycle. 2007 Feb;6(4):385-9.

Bowers RR, Lane MD. Wnt signaling and adipocyte lineage commitment. Cell Cycle. 2008 May;7(9):1191-6.

Brigelius-Flohé R, Flohé L. Ascorbic acid, cell proliferation, and cell differentiation in culture. Subcell Biochem. 1996;25:83-107.

Chang HR, Kim HJ, Xu X, Ferrante AW, Jr. Macrophage and adipocyte IGF1 maintain adipose tissue homeostasis during metabolic stresses. Obesity (Silver Spring). 2016 Jan 24(1):172-83.

Chatterjee TK, Idelman G, Blanco V, Blomkalns AL, Piegore M, Weintraub DS, et al. Histone deacetylase 9 is a negative regulator of adipogenic differentiation. J Biol Chem. 2011 Aug; 286(31):27836-47.

Chen J, Shi ZD, Ji X, Morales J, Zhang J, Kaur N, et al. Enhanced osteogenesis of human mesenchymal stem cells by periodic heat shock in self-assembling peptide hydrogel. Tissue Eng Part A. 2013 Mar;19(5-6):716-28.

Chen Q, Shou P, Zheng C, Jiang M, Cao G, Yang $\mathrm{Q}$, et al. Fate decision of mesenchymal stem cells: adipocytes or osteoblasts? Cell Death Differ. 2016a Jul;23(7):1128-39.

Chen YQ, Liu YS, Liu YA, Wu YC, Del Álamo JC, Chiou A, et al. Bio- chemical and physical characterizations of mesenchymal stromal cells along the time course of directed differentiation. Sci Rep. 2016b Aug;6(1):31547.
Choi KM, Seo YK, Yoon HH, Song KY, Kwon SY, Lee HS, et al. Effect of ascorbic acid on bone marrow-derived mesenchymal stem cell proliferation and differentiation. J Biosci Bioeng. 2008 Jun;105(6):586-94.

Choy L, Skillington J, Derynck R. Roles of autocrine TGF- $\beta$ receptor and Smad signaling in adipocyte differentiation. J Cell Biol. 2000 May;149(3):667-82.

Datta P, Sharma A, Pal B, Mohit K. The role of adipokines and adipogenesis in the pathogenesis of osteoarthritis. Cytokine effector functions in tissues. Amsterdam: Elsevier; 2017. pp. 99-107.

Dennis G Jr, Sherman BT, Hosack DA, Yang J, Gao W, Lane HC, et al. DAVID: database for annotation, visualization, and integrated discovery. Genome Biol. 2003;4(5):3.

Diekman BO, Estes BT, Guilak F. The effects of BMP6 overexpression on adipose stem cell chondrogenesis: interactions with dexamethasone and exogenous growth factors. J Biomed Mater Res A. 2010 Jun;93(3):9941003.

Edmondson R, Broglie JJ, Adcock AF, Yang L. Three-dimensional cell culture systems and their applications in drug discovery and cellbased biosensors. Assay Drug Dev Technol. 2014 May;12(4):207-18.

Entenmann G, Hauner H. Relationship between replication and differentiation in cultured human adipocyte precursor cells. Am J Physiol. 1996 Apr;270(4 Pt 1):C1011-6.

Fajas L. Adipogenesis: a cross-talk between cell proliferation and cell differentiation. Ann Med. 2003;35(2):79-85.

Fatima LA, Campello RS, Santos RS, Freitas HS, Frank AP, Machado UF, et al. Estrogen receptor 1 (ESR1) regulates VEGFA in adipose tissue. Sci Rep. 2017 Dec;7(1):16716.

Frith JE, Mills RJ, Hudson JE, Cooper-White JJ. Tailored integrin-extracellular matrix interactions to direct human mesenchymal stem cell differentiation. Stem Cells Dev. 2012 Sep; 21(13):2442-56.

Fumoto T, Yamaguchi T, Hirose F, Osumi T. Orphan nuclear receptor Nur77 accelerates the initial phase of adipocyte differentiation in 3T3-L1 cells by promoting mitotic clonal expansion. J Biochem. 2007 Feb;141(2):181-92.

Garcés C, Ruiz-Hidalgo MJ, Font de Mora J, Park C, Miele L, Goldstein J, et al. Notch-1 controls the expression of fatty acid-activated transcription factors and is required for adipogenesis. J Biol Chem. 1997 Nov;272(47):29729-34.

Ge C, Cawthorn WP, Li Y, Zhao G, Macdougald OA, Franceschi RT. Reciprocal control of osteogenic and adipogenic differentiation by ERK/MAP kinase phosphorylation of Runx2 and PPAR $\gamma$ transcription factors. J Cell Physiol. 2016 Mar;231(3):587-96.

Harrington M, Pond-Tor S, Boney CM. Role of epidermal growth factor and ErbB2 receptors in 3T3-L1 adipogenesis. Obesity (Silver Spring). 2007 Mar;15(3):563-71.
Hu L, Yang G, Hägg D, Sun G, Ahn JM, Jiang N, et al. IGF1 promotes adipogenesis by a lineage bias of endogenous adipose stem/progenitor cells. Stem Cells. 2015 Aug;33(8): 2483-95.

James AW. Review of signaling pathways governing MSC osteogenic and adipogenic differentiation. Scientifica (Cairo). 2013;2013: 684736.

Jeon Y, Lee MS, Cheon YP. Decreased contact inhibition in mouse adipose mesenchymal stem cells. Dev Reprod. 2012 Dec;16(4):329_ 38.

Jo A, Denduluri S, Zhang B, Wang Z, Yin L, Yan $Z$, et al. The versatile functions of Sox 9 in development, stem cells, and human diseases. Genes Dis. 2014 Dec;1(2):149-61.

Kakudo N, Shimotsuma A, Kusumoto K. Fibroblast growth factor-2 stimulates adipogenic differentiation of human adipose-derived stem cells. Biochem Biophys Res Commun. 2007 Jul 27;359(2):239-44.

Kang Q, Song WX, Luo Q, Tang N, Luo J, Luo X, et al. A comprehensive analysis of the dual roles of BMPs in regulating adipogenic and osteogenic differentiation of mesenchymal progenitor cells. Stem Cells Dev. 2009 May; 18(4):545-59.

Kim S, Ahn C, Bong N, Choe S, Lee DK. Biphasic effects of FGF2 on adipogenesis. PLoS One. 2015;10(3):e0120073

Kisiday J, Jin M, Kurz B, Hung H, Semino C, Zhang S, et al. Self-assembling peptide hydrogel fosters chondrocyte extracellular matrix production and cell division: implications for cartilage tissue repair. Proc Natl Acad Sci USA. 2002 Jul;99(15):9996-10001.

Kooistra MR, Dubé N, Bos JL. Rap1: a key regulator in cell-cell junction formation. J Cell Sci. 2007 Jan;120(Pt 1):17-22.

Lee S, Park JR, Seo MS, Roh KH, Park SB, Hwang JW, et al. Histone deacetylase inhibitors decrease proliferation potential and multilineage differentiation capability of human mesenchymal stem cells. Cell Prolif. 2009 Dec; 42(6):711-20.

Lee SE, Kang SG, Choi MJ, Jung SB, Ryu MJ, Chung HK, et al. Growth Differentiation Factor 15 Mediates Systemic Glucose Regulatory Action of T-Helper Type 2 Cytokines. Diabetes. 2017 Nov;66(11):2774-88.

Li HX, Luo X, Liu RX, Yang YJ, Yang GS. Roles of $\mathrm{Wnt} / \beta$-catenin signaling in adipogenic differentiation potential of adipose-derived mesenchymal stem cells. Mol Cell Endocrinol. 2008 Sep;291(1-2):116-24.

Liu Y, Berendsen AD, Jia S, Lotinun S, Baron R, Ferrara $\mathrm{N}$, et al. Intracellular VEGF regulates the balance between osteoblast and adipocyte differentiation. J Clin Invest. 2012 Sep;122(9): 3101-13

MacDougald OA, Lane MD. Transcriptional regulation of gene expression during adipocyte differentiation. Annu Rev Biochem. 1995; 64(1):345-73. 
Maeda H, Wada N, Tomokiyo A, Monnouchi S, Akamine A. Prospective potency of TGF- $\beta 1$ on maintenance and regeneration of periodontal tissue. International review of cell and molecular biology. Amsterdam: Elsevier; 2013. pp. 283-367.

Mannello F, Tonti GA, Bagnara GP, Papa S. Role and function of matrix metalloproteinases in the differentiation and biological characterization of mesenchymal stem cells. Stem Cells. 2006 Mar;24(3):475-81.

Marcon BH, Shigunov P, Spangenberg L, Pereira IT, de Aguiar AM, Amorín R, et al. Cell cycle genes are downregulated after adipogenic triggering in human adipose tissue-derived stem cells by regulation of mRNA abundance. Sci Rep. 2019 Apr;9(1): 5611.

Markowitz SD, Berger NA, editors. Energy balance and gastrointestinal cancer. Berlin: Springer; 2012.

Mathieu PS, Loboa EG. Cytoskeletal and focal adhesion influences on mesenchymal stem cell shape, mechanical properties, and differentiation down osteogenic, adipogenic, and chondrogenic pathways. Tissue Eng Part B Rev. 2012 Dec;18(6):436-44.

McBeath R, Pirone DM, Nelson CM, Bhadriraju $\mathrm{K}$, Chen CS. Cell shape, cytoskeletal tension, and RhoA regulate stem cell lineage commitment. Dev Cell. 2004 Apr;6(4):483-95.

Modica S, Wolfrum C. The dual role of BMP4 in adipogenesis and metabolism. Adipocyte. 2017 Apr;6(2):141-6.

Muruganandan S, Roman AA, Sinal CJ. Adipocyte differentiation of bone marrow-derived mesenchymal stem cells: cross talk with the osteoblastogenic program. Cell Mol Life Sci. 2009 Jan;66(2):236-53.

Musri MM, Gomis R, Párrizas M. A chromatin perspective of adipogenesis. Organogenesis. 2010 Jan-Mar;6(1):15-23.

Neumann K, Endres M, Ringe J, Flath B, Manz R, Häupl T, et al. BMP7 promotes adipogenic but not osteo-/chondrogenic differentiation of adult human bone marrow-derived stem cells in high-density micro-mass culture. J Cell Biochem. 2007 Oct;102(3):62637.

Okada A, Yamasaki S, Koga T, Kawashiri SY, Tamai M, Origuchi T, et al. Adipogenesis of the mesenchymal stromal cells and bone oedema in rheumatoid arthritis. Clin Exp Rheumatol. 2012 May-Jun;30(3):332-7.

Park A, Kim WK, Bae KH. Distinction of white, beige and brown adipocytes derived from mesenchymal stem cells. World J Stem Cells. 2014 Jan 26;6(1):33-42.

Park JS, Kim M, Song NJ, Kim JH, Seo D, Lee JH, et al. A reciprocal role of the Smad4-Taz axis in osteogenesis and adipogenesis of mesenchymal stem cells. Stem Cells. 2019 Mar; 37(3):368-81.

Patel NG, Kumar S, Eggo MC. Essential role of fibroblast growth factor signaling in preadipoctye differentiation. J Clin Endocrinol Metab. 2005 Feb;90(2):1226-32.
Peinado JR, Jimenez-Gomez Y, Pulido MR, Ortega-Bellido M, Diaz-Lopez C, Padillo FJ, et al. The stromal-vascular fraction of adipose tissue contributes to major differences between subcutaneous and visceral fat depots. Proteomics. 2010 Sep;10(18):3356-66.

Pinnick KE, Nicholson G, Manolopoulos KN, McQuaid SE, Valet P, Frayn KN, et al.; MolPAGE Consortium. Distinct developmental profile of lower-body adipose tissue defines resistance against obesity-associated metabolic complications. Diabetes. 2014 Nov; 63(11):3785-97.

Qian SW, Li X, Zhang YY, Huang HY, Liu Y, Sun $\mathrm{X}$, et al. Characterization of adipocyte differentiation from human mesenchymal stem cells in bone marrow. BMC Dev Biol. 2010 May; 10(1):47.

Ramazzotti G, Ratti S, Fiume R, Follo MY, Billi AM, Rusciano I, et al. Phosphoinositide 3 kinase signaling in human stem cells from reprogramming to differentiation: a tale in cytoplasmic and nuclear compartments. Int J Mol Sci. 2019 Apr;20(8):2026.

Ruiz-Ojeda FJ, Rupérez AI, Gomez-Llorente C Gil A, Aguilera CM. Cell models and their application for studying adipogenic differentiation in relation to obesity: a review. Int $\mathrm{J} \mathrm{Mol}$ Sci. 2016a Jun;17(7):1040.

Schwartz MA, Assoian RK. Integrins and cell proliferation: regulation of cyclin-dependent kinases via cytoplasmic signaling pathways. J Cell Sci. 2001 Jul;114(Pt 14):2553-60.

Scioli MG, Bielli A, Gentile P, Mazzaglia D, Cervelli V, Orlandi A. The biomolecular basis of adipogenic differentiation of adipose-derived stem cells. Int J Mol Sci. 2014 Apr 16;15(4):6517-26.

Shen H, Gelberman RH, Silva MJ, Sakiyama-Elbert SE, Thomopoulos S. BMP12 induces tenogenic differentiation of adipose-derived stromal cells. PLoS One. 2013 Oct; 8(10):e77613.

Song F, Jiang D, Wang T, Wang Y, Lou Y, Zhang $\mathrm{Y}$, et al. Mechanical stress regulates osteogenesis and adipogenesis of rat mesenchymal stem cells through PI3K/Akt/GSK-3 $\beta / \beta$ catenin signaling pathway. Biomed Res Int. 2017;2017:6027402.

Sonowal H, Kumar A, Bhattacharyya J, Gogoi PK, Jaganathan BG. Inhibition of actin polymerization decreases osteogeneic differentiation of mesenchymal stem cells through p38 MAPK pathway. J Biomed Sci. 2013 Sep 26; 20:71.

Stöckl S, Bauer R, Bosserhoff A, Göttl C, Grifka J, Grässel S. Sox9 modulates cell survival and adipogenic differentiation of multipotent adult rat mesenchymal stem cells. J Cell Sci. 2013 Jul;126(Pt 13):2890-902.

Sul HS. Minireview: Pref-1: role in adipogenesis and mesenchymal cell fate. Mol Endocrinol. 2009 Nov;23(11):1717-25.

Talele NP, Fradette J, Davies JE, Kapus A, Hinz B. Expression of alpha-smooth muscle actin determines the fate of mesenchymal stromal cells. Stem Cell Reports. 2015 Jun 9;4(6): 1016-30.
Tibbitt MW, Anseth KS. Hydrogels as extracellular matrix mimics for $3 \mathrm{D}$ cell culture. Biotechnol Bioeng. 2009 Jul;103(4):655-63.

Tojkander S, Gateva G, Lappalainen P. Actin stress fibers-assembly, dynamics and biological roles. J Cell Sci. 2012 Apr;125(Pt 8):185564.

Wang QA, Scherer PE, Gupta RK. Improved methodologies for the study of adipose biology: insights gained and opportunities ahead. J Lipid Res. 2014 Apr;55(4):605-24.

Wang Y, Sul HS. Pref-1 regulates mesenchymal cell commitment and differentiation through Sox9. Cell Metab. 2009 Mar;9(3):287-302.

Watanabe M, Takahashi H, Saeki Y, Ozaki T, Itoh S, Suzuki M, et al. The E3 ubiquitin ligase TRIM23 regulates adipocyte differentiation via stabilization of the adipogenic activator PPARү. eLife. 2015 Apr;4:e05615.

Wells RG. The role of matrix stiffness in regulating cell behavior. Hepatology. 2008 Apr; 47(4):1394-400.

Wolins NE, Quaynor BK, Skinner JR, Tzekov A, Park C, Choi K, et al. OP9 mouse stromal cells rapidly differentiate into adipocytes: characterization of a useful new model of adipogenesis. J Lipid Res. 2006 Feb;47(2):450-60.

Wong A, Ghassemi E, Yellowley CE. Nestin expression in mesenchymal stromal cells: regulation by hypoxia and osteogenesis. BMC Vet Res. 2014 Aug;10(1):173.

Yokoi H, Kinoshita T, Zhang S. Dynamic reassembly of peptide RADA16 nanofiber scaffold. Proc Natl Acad Sci USA. 2005 Jun; 102(24):8414-9.

Zamani N, Brown CW. Emerging roles for the transforming growth factor-beta superfamily in regulating adiposity and energy expenditure. Endocr Rev. 2011 Jun;32(3):387-403.

Zebda N, Dubrovskyi O, Birukov KG. Focal adhesion kinase regulation of mechanotransduction and its impact on endothelial cell functions. Microvasc Res. 2012 Jan;83(1):71-81.

Zhang P, Li J, Qi Y, Zou Y, Liu L, Tang X, et al. Vitamin $\mathrm{C}$ promotes the proliferation of human adipose-derived stem cells via p53-p21 pathway. Organogenesis. 2016 Jul;12(3):14351.

Zhang S, Holmes T, Lockshin C, Rich A. Spontaneous assembly of a self-complementary oligopeptide to form a stable macroscopic membrane. Proc Natl Acad Sci USA. 1993 Apr; 90(8):3334-8.

Zhang S, Holmes TC, DiPersio CM, Hynes RO, Su X, Rich A. Self-complementary oligopeptide matrices support mammalian cell attachment. Biomaterials. 1995 Dec;16(18):138593.

Zhao X, Zhang S. Fabrication of molecular materials using peptide construction motifs. Trends Biotechnol. 2004 Sep;22(9):470-6.

Zuttion MS, Wenceslau CV, Lemos PA, Takimura C, Kerkis I. Adipose tissue-derived stem cells and the importance of animal model standardization for pre-clinical trials. Rev Bras Cardiol Invasiva. 2013;21(3): 281-7. 